C E N T E R F O R

E C O N O M I C

B E H A V I O R \&

I N E Q U A L I T Y

CEBI WORKING PAPER SERIES

Working Paper 05/19

SUBOPTIMAL PATERNALISM: ABILITY, BENEVOLESANCE, AND SELF-SELECTION IN CHOOSING FOR OTHERS

David Dreyer Lassen

Felix Sebastian Døssing

ISSN 2596-44TX

\title{
CEBI
}

Department of Economics University of Copenhagen www.cebi.ku.dk 


\title{
Suboptimal paternalism: Ability, benevolence, and self-selection in choosing for others*
}

\author{
Felix Sebastian Døssing and David Dreyer Lassen \\ Center for Economic Behavior and Inequality \\ Department of Economics \\ University of Copenhagen
}

August 2019

\begin{abstract}
Discussions about the legitimacy and welfare consequences of paternalistic interventions usually begin with the assumption that regulators are both benevolent and competent. We present experimental evidence that neither need be the case. In our experiment, individuals choose whether to restrict the choice of another participant and we see that regulation, on average, decreases choice efficiency. While more competent regulators are more likely to restrict choice sets in order to improve welfare for subjects when they use their regulatory privilige, selection into being an active regulator is unrelated to competence. The propensity for kind regulation is increasing in own competence, while the propensity for unkind regulation is both negatively related to own competence and positively related to the competence of the subject.
\end{abstract}

\footnotetext{
*We gratefully acknowledge funding from ERC Consolidator Grant no. 313673 and CEBI. CEBI is financed by a grant from the Danish National Research Foundation. We thank Niclas Berggren, Daniel Mahler, Marco Piovesan and seminar and workshop participants at Copenhagen 2018 and Aarhus 2019 for comments. Comments welcome at ddl@econ.ku.dk
} 
Should people be allowed to make bad choices that only hurt themselves? Who should intervene if not? Are we, as humans and as societies, willing to trade-off freedom and individual autonomy against normative ideals of good or optimal behavior? Paternalism, the act of limiting the freedom of someone in order to help that same individual, is at the core of frequent policy debates involving difficult questions of whether regulating choice, the outcomes of which only causes harm to the chooser, can be justified. Examples are abundant: Should we prohibit or tax cigarettes in order to save individuals from increasing their own risk of cancer? Should seat belts and bike helmets be mandatory? Should we require by law that individuals save for retirement and that people sign up for health and unemployment insurance?

The question has been controversial at least since John Stuart Mill [1], who argued that individuals should enjoy considerable freedom, including the freedom to harm themselves. Since revived by Feinberg [2] and Dworkin [3] in the early 1970s, the debate has been extensive in philosophy and ethics $[4,5,6,7]$, social work $[8,9]$, public policy $[10,11,12]$, law $[10,13,14]$, health, bioethics and neuroethics $[15,16,17]$, and economics [18, 19]. In large part, the more recent of these works are inspired by evidence from psychology and behavioral economics on biased decision-making and choice inconsistencies, with people failing to internalize the full set of consequences of decisions for their own welfare [20, 21]. This new and growing scientific basis for choice imperfections has led to discussions about asymmetric or libertarian paternalism $[22,23]$ and nudging $[24,25]$. This adds to the core discussion of classical paternalism in the presence of differences in decision-making competences.

This paper investigates two fundamental questions of positive paternalism: (1) Do regulators use paternalistic policies in order to help their subjects and (2) Does choice regulation pass from more competent regulators to less competent subjects? We analyze in an experimental setting the decision to exercise choice on behalf of others - and the content of that choice - in a analytically simple case of choice under risk. The experimental setting reflects that paternalism by definition entails assumptions of beneficent actions by a regulator affecting or overriding choices or choice sets of a subject under the, often implicit, assumption that the regulator can make "better" decisions than the subject. Typically, such advanced decision-making abilities are argued to be the result of superior cognitive ability and farsightedness, informational advantages or experience and professional knowledge, such as doctors making decisions on behalf of their patients $[26,13,7]$.

While there is no shortage of normative analyses of paternalism and choice restrictions, 
there is a distinct lack of positive analyses of the act of exercising paternalism. ${ }^{1}$ Studying paternalistic behavior is complicated by the fact that in practice paternalism will often, if not always, be confounded by potential concerns that the actions of the subject may have indirect consequences for the regulator. This could for example be through fiscal externalities arising from the consequences of inferior choices being paid for or mitigated by a public including the regulator, e.g. the state. Using a controlled experimental setting, we create a choice setting were choice restrictions may only affect the regulator through her social preferences.

Existing experimental work on choosing for others has on the one hand focused on how people make choices for others given that they have to [29], and on the other hand on how those subjected to paternalistic regulation, the subjects, view or value having decisions made on their behalf [30]. It has not focused on whether individuals take upon themselves to regulate in the first place and has not explored the structure of regulators' choice to exercise paternalism in a setting involving differences in competence.

We provide a novel framework in order to study the choice of paternalism based on incentivized experiments. To make this operational, we require a transparent, easy to measure competence score and a measure of intentions. ${ }^{2}$ We measure participants' competence in an incentivized test on probability concepts. In our setting, the regulator chooses whether and how the choice set of the subject should be restricted, after learning about the competence levels of both parties. At the same time, the regulator has herself carried out the incentivized choice, allowing us, by revealed preference, to infer what she believes to be optimal for herself.

We explicitly do not model the reasons for engaging in choice restrictions, nor for helping or harming conditional on such restrictions. Regulators do not get any payoff from choosing to regulate, regardless of whether the choice to regulate helps or harms. As such, they may be driven by a general principle of beneficence as envisioned by Hume [31] and Mill [32], a principle of non-maleficence ("First do no harm") - or they may be meddlesome [33], spiteful [34], seeking power [35] or moralizing [36]. The lack of feedback from the regulator's choice regarding paternalism to her own payoff explicitly excludes the case of concerns over associated costs or fiscal externalities, focusing on the case of imposing choice restrictions to save individuals from themselves rather than to save the public purse from increased costs from collateral expenditures.

\footnotetext{
${ }^{1}$ A number of studies examine stated attitudes towards nudging [27] and, in rarer cases, attitudes towards paternalism on specific issues [28], but do not consider behavior.

${ }^{2}$ Both the intentions behind - and the welfare consequences of - paternalistic interventions are difficult to measure. Here, intentions refer to the limited choice between \{help, harm, indifferent\} while welfare is simply equated with payoff, the ordering of which is strict under the lotteries we consider.
} 


\section{Design and implementation}

The experiment was divided into three main parts. First, the participants completed an incentivized test, ${ }^{3}$ which was designed to measure their ability to comprehend various concepts in probability theory. On the test screen, as well as on lottery choice screens, participants had access to a calculator, which could help them with simple calculations. The test took 30 minutes and participants were not able to move forward in the experiment before the time had passed.

In the second main part of the experiment, subjects made a choice between two lotteries in three different pairs. We refer to this as their unregulated choice. Participants were informed that one of the lottery-pairs would be randomly chosen to be consequential. The lottery pairs were selected to represent different concepts of stochastic dominance, i.e. desirability under risk. ${ }^{4}$ Throughout, for the given concept of stochastic dominance, we will refer to the dominating lottery as being superior and the dominated lottery as inferior. We refer to the first lottery-pair as Expected Loss (EL). The EL lottery-pair involved both a firstorder stochastic dominance relation and the fact that the inferior lottery had an expected return below one, whereas the superior lottery had an expected return above one. The First-order Stochastic Dominance lottery-pair (FOSD) featured two alternatives, which both gave an expected return above one, but where one dominated the other in terms of firstorder stochastic dominance. The Second-order Stochastic Dominance lottery-pair (SOSD) featured two alternatives, which both had the same expected return above one, but where one dominated the other in terms of second-order stochastic dominance. The lottery pairs thus varied in the subtlety of their dominance relation [37], a difference which is also reflected in the results. The position on the screen of all lottery pairs and lotteries within lottery pairs were randomized, but kept constant for each participant throughout the experiment. In addition, lotteries were given generic names ("Lottery A" and "Lottery B"), which were also randomized and kept constant.

In the third main part of the experiment subjects decided whether to remove lotteries from the choice set of another participant. They decided whether they wished to remove one of the two lotteries from each lottery pair, and if so, which lottery they wanted to remove from the pair. We refer to this choice as the regulation choice. The lottery pairs in the

\footnotetext{
${ }^{3}$ One participant in each session was randomly selected to have 20 points for each correct answer added to that persons payoff. With 20 questions and a conversion rate of 0.2 , the maximal payoff from the test was 80 DKK.

${ }^{4}$ The stochastic dominance concepts, as well as their implementation in the lottery pairs, are explained in detail in section 4 of the supplementary materials
} 
regulation choice were identical to those they had encountered previously in the unregulated choice. Each participant made a regulation choice for five randomly matched participants. For each participant, one of their regulated choices was chosen to be consequential for their ultimate payoff. It was emphasized in the instructions that any participant that was affected by one's choices would never make choices that affected oneself in the experiment. During the regulation choice, regulators were provided with information regarding their own as well as the subject's test score. ${ }^{5}$ In order to anchor the information and make it salient, the test scores were presented in a chart, which showed the distribution of test scores in the session.

The experiment was implemented using oTree [38] and recruitment was handled using ORSSE [39]. Pre-registration was done using at the Open Science Framework webpage (see section 5 of the supplementary materials). 178 individuals participated in the experiment at the Laboratory for Experimental Economics (LEE) at the University of Copenhagen over a period of two weeks in December 2017.

\section{Results}

In contrast to the normative grounds for paternalism, subjects in our experiment do worse when choices are regulated. Figure 1.A compares the probability of choosing the superior option for unregulated and regulated choices across the three lottery choices. As expected, comprehension is highest for the EL lottery choice, where 91 percent choose the superior lottery when not regulated. For the two other choices, comprehension is lower (67.4 pct. and 66.9 pct.), but still significantly above what would result from random choice. However, regulation reduces the probability of realizing the superior lottery by 20.3 percentage points for the EL choice, 6.2 percentage points for FOSD lottery and 7.0 percentage points for the SOSD lottery $\left(p<.01\right.$ in all cases $\left.^{6}\right)$. The negative effect of regulation is larger when when comprehension is higher.

What drives the clear negative effect of allowing for choice regulation? The main prerequisite for efficient choice regulation - and for paternalism in the first place - is that the more competent help the less competent make better choices. Relating test scores to regulatory behavior, however, shows a different picture. Although test scores significantly predict superior lottery choice in the unregulated choice setting for both the EL lottery pair and the FOSD

\footnotetext{
${ }^{5}$ A subsample was provided only with information regarding their subject's test score, not their own. This was done in order to test for possible effects of overconfidence. We include information dummies in regressions when relevant.

${ }^{6}$ We present results for all choices with standard errors clustered at the regulator level. For various robustness checks see section 3 of the supplementary materials.
} 
lottery pair (See table S2 in the supplementary materials), regulators are not responsive to test scores when deciding whether to restrict the choices of their subject. This is shown clearly in Figure 1.B, which shows estimates from a linear probability model relating own test score and subject test score to extensive margin regulation choice. The estimates are insignificant for all lottery pairs and the general pattern contradicts the normative grounds for paternalistic intervention: Regulators are less likely to restrict choices when their own competence is higher and more likely to restrict choices when their subject's competence is higher.

While regulators do not respond to test scores when choosing whether to restrict choices, test scores are significantly related to what kind of restrictions are applied. Figure 1.C relates test scores to whether regulators chose to remove the superior or inferior lottery. We focus on the EL lottery here, because comprehension was lower in the two additional lottery choices, which limits the analysis of intentionality of restriction choices. As the test score of the regulator increases, she becomes less likely to remove the superior lottery and more likely to remove the inferior lottery. As the test score of the subject increases, the regulator becomes more likely to remove the superior lottery and less likely to remove the inferior lottery. The slope is significantly different from zero both for own test score $(p<.01$ in both cases) and for subject test score $(p<.01$ for removing superior, $p=.03$ for removing inferior).

By assuming that participants always choose what they consider the (weakly) better option in the unregulated choice setting where they choose for themselves, we can categorize restrictive actions according to regulator intentions. We label a restriction as kind if the regulator removes the lottery which she did not choose herself and thereby reduces the choice set of the subject to the lottery which the regulator chose for herself. Likewise, we label a regulatory action as unkind if the regulator removes the lottery which she chose herself. Figure 1.D shows estimates from a regression of regulatory intention on regulator test score and subject test score. For the EL choice, focusing on intentions produces the same overall picture as Figure 1.C. Apart from this, we see that unkind restrictions are significantly related to own test score for the FOSD choice $(p=.025)$ as well as for the SOSD choice $(p<.01)$. Kind restrictions are not significantly related to own test score for the FOSD and SOSD choices, although estimates suggest more competent regulators are also more likely to be kind for these two choice. While subject test score is positively related to the propensity to be unkind $(p=.013)$ and somewhat related to the propensity to be kind $(p=.106)$ for the EL choice, we do not see any relation for the two other lotteries. 


\section{Discussion}

We present a first experimental investigation of two core assumptions of normative paternalism: (1) choice regulations are used benevolently; and (2) choice restrictions are implemented by the more competent for the benefit of the less competent. While recent work has investigated the value of autonomy and freedom to choose from the perspective of individuals being chosen for [40,30], we focus on the decision to exercise paternalism by deciding whether and what to choose for others. Our experimental setup incorporates the decision of whether to choose for others, differences in choice abilities and information about these differences, and an explicit lack of direct incentives to help or assist, including a lack of pecuniary incentives through fiscal externalities, beyond the general principle of beneficence.

Our an empirical approach highlights new aspects of the normative discussion on paternalism: First, we cannot expect choice regulation to necessarily by used in a benevolent fashion. While the concept paternalism assumes benevolence by definition, discussions of choice regulation would do well to take a broader scope; our results on how own and others' competence levels affect decisions of choice regulation suggests the presence of spite [41,34], envy or malice [42], but this should be examined in more detail and across settings. Second, while there is valid grounds for "expert paternalism" with the competent also acting more benevolently, it is by no means given that the more competent will be more likely to implement choice regulations or the the less competent will refrain from exercising paternalism.

In general, our positive analysis suggests that choice paternalism is suboptimal: Many regulators enact harmful choice restrictions and a large fraction of these do not choose for their subjects what they chose for themselves. This adds to concerns that modern paternalism motivated by choice biases may not result in better aggregate outcomes [19, 43]; in particular, while "experts" may be more helpful if they have to choose [13], they are no more likely than low competence regulators to put themselves in a position of deciding for others. We are currently examining the application of the principle of beneficence across occupations as well as paternalism in effort choice. 


\section{References}

[1] John Stuart Mill. On liberty and other essays. Oxford University Press, USA, 1998.

[2] Joel Feinberg. Legal paternalism. 1(1):105-124, 1971.

[3] Gerald Dworkin. Paternalism. The Monist, pages 64-84, 1972.

[4] Bernard Gert and Charles M Culver. The justification of paternalism. Ethics, 89(2):199210, 1979.

[5] Richard J Arneson. Mill versus paternalism. Ethics, 90(4):470-489, 1980.

[6] Amartya Sen. Well-being, agency and freedom: The Dewey Lectures 1984. The Journal of Philosophy, 82(4):169-221, 1985.

[7] Sarah Conly. Against Autonomy: Justifying Coercive Paternalism. Cambridge University Press, 2012.

[8] Donald VanDeVeer. Autonomy respecting paternalism. Social Theory and Practice, 6(2):187-207, 1980.

[9] Marcia Abramson. The autonomy-paternalism dilemma in social work practice. Social Casework, 66(7):387-393, 1985.

[10] Deborah M Weiss. Paternalistic pension policy: psychological evidence and economic theory. The University of Chicago Law Review, 58(4):1275-1319, 1991.

[11] Bill New. Paternalism and public policy. Economics \& Philosophy, 15(1):63-83, 1999.

[12] Julian Le Grand and Bill New. Government paternalism: Nanny state or helpful friend? Princeton University Press, 2015.

[13] Jeremy A Blumenthal. Expert paternalism. Florida Law Review, 64:721, 2012.

[14] Cass R Sunstein. The storrs lectures: Behavioral economics and paternalism. Yale LJ, 122:1826, 2012.

[15] Jonathan D Moreno. Neuroethics: an agenda for neuroscience and society. Nature Reviews Neuroscience, 4(2):149, 2003. 
[16] Bernard Gert, Charles M Culver, and K Danner Clouser. Bioethics: A systematic approach. Oxford University Press, USA, 2006.

[17] David R Buchanan. Autonomy, paternalism, and justice: Ethical priorities in public health. American Journal of Public Health, 98(1):15-21, 2008.

[18] Ted O'Donoghue and Matthew Rabin. Studying optimal paternalism, illustrated by a model of sin taxes. American Economic Review, 93(2):186-191, 2003.

[19] Edward Glaeser. Psychology and paternalism. U Chi L Rev, 73:133, 2006.

[20] Richard J Herrnstein, George F Loewenstein, Drazen Prelec, and William Vaughan Jr. Utility maximization and melioration: Internalities in individual choice. Journal of behavioral decision making, 6(3):149-185, 1993.

[21] G Loewenstein and E Haisley. The economist as therapist: Methodological ramifications of 'light' paternalism /ed. by a. caplin, a. schotter. Perspectives on the Future of Economics: Positive and Normative Foundations. The Handbook of Economic Methodologies, 1.

[22] Colin Camerer, Samuel Issacharoff, George Loewenstein, Ted O'Donoghue, and Matthew Rabin. Regulation for conservatives: Behavioral economics and the case for" asymmetric paternalism". University of Pennsylvania Law Review, 151(3):1211-1254, 2003.

[23] Richard H Thaler and Cass R Sunstein. Libertarian paternalism. American economic review, 93(2):175-179, 2003.

[24] Richard H Thaler and Cass R Sunstein. Nudge: Improving decisions about health, wealth, and happiness. Yale University Press, 2008.

[25] Luc Bovens. The ethics of nudge. In Preference change, pages 207-219. Springer, 2009.

[26] Danny Scoccia. In defense of hard paternalism. Law and Philosophy, 27(4):351-381, 2008.

[27] Cass R Sunstein, Lucia A Reisch, and Julius Rauber. A worldwide consensus on nudging? not quite, but almost. Regulation \& Governance, 12(1):3-22, 2018.

[28] David Dreyer Lassen and Daniel Gerzon Mahler. Free to choose or free to lose? Manuscript, Center for Economic Behavior and Inequality, University of Copenhagen, 2019. 
[29] Ola Andersson, Håkan J Holm, Jean-Robert Tyran, and Erik Wengström. Deciding for others reduces loss aversion. Management Science, 62(1):29-36, 2014.

[30] Björn Bartling, Ernst Fehr, and Holger Herz. The intrinsic value of decision rights. Econometrica, 82(6):2005-2039, 2014.

[31] David Hume. An enquiry concerning the principles of morals: a critical edition, volume 4. Oxford University Press, 2006.

[32] John Stuart Mill. Utilitarianism. Utilitarianism and on Liberty: Including Mill's 'Essay on Bentham'and selections from the writings of Jeremy Bentham and John Austin, pages 181-235, 2003.

[33] Julian H Blau. Liberal values and independence. The Review of Economic Studies, 42(3):395-401, 1975.

[34] Ernst Fehr and Klaus M Schmidt. The economics of fairness, reciprocity and altruismexperimental evidence and new theories. Handbook of the economics of giving, altruism and reciprocity, 1:615-691, 2006.

[35] Ernst Fehr, Holger Herz, and Tom Wilkening. The lure of authority: Motivation and incentive effects of power. American Economic Review, 103(4):1325-59, 2013.

[36] Michael Bang Petersen. Moralization as protection against exploitation: Do individuals without allies moralize more? Evolution and Human Behavior, 34(2):78-85, 2013.

[37] Moshe Levy and Haim Levy. Testing for risk aversion: a stochastic dominance approach. Economics Letters, 71(2):233-240, 2001.

[38] Daniel L. Chen, Martin Schonger, and Chris Wickens. otree - an open-source platform for laboratory, online, and field experiments. Journal of Behavioral and Experimental Finance, 9:88 - 97, 2016.

[39] Ben Greiner. Subject pool recruitment procedures: organizing experiments with orsee. Journal of the Economic Science Association, 1(1):114-125, Jul 2015.

[40] David Owens, Zachary Grossman, and Ryan Fackler. The control premium: A preference for payoff autonomy. American Economic Journal: Microeconomics, 6(4):138-61, 2014. 
[41] Madan M. Pillutla and J.Keith Murnighan. Unfairness, anger, and spite: Emotional rejections of ultimatum offers. Organizational Behavior and Human Decision Processes, 68(3):208 - 224, 1996.

[42] Steven R Beckman, John P Formby, W James Smith, and Buhong Zheng. Envy, malice and pareto efficiency: An experimental examination. Social Choice and Welfare, $19(2): 349-367,2002$.

[43] Niclas Berggren. Time for behavioral political economy? an analysis of articles in behavioral economics. The Review of Austrian Economics, 25(3):199-221, 2012. 


\section{Supplementary Materials}

Figures S1-S12

Tables S1-S8 
A. Effect of regulation on choice efficiency

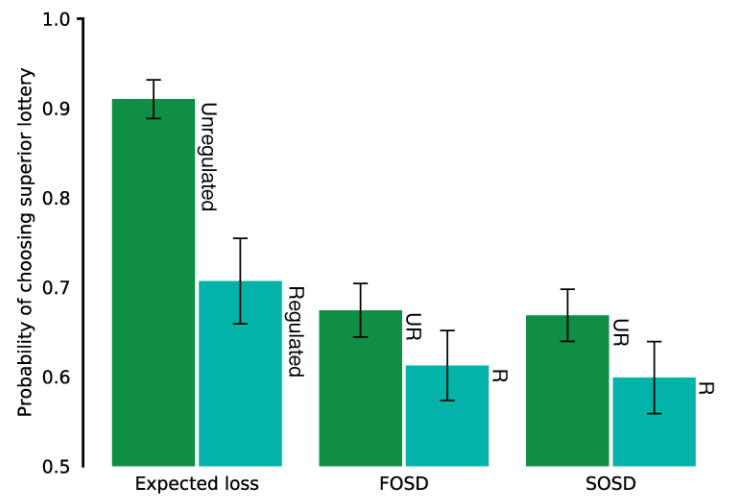

\section{B. Deciding whether to restrict choices}

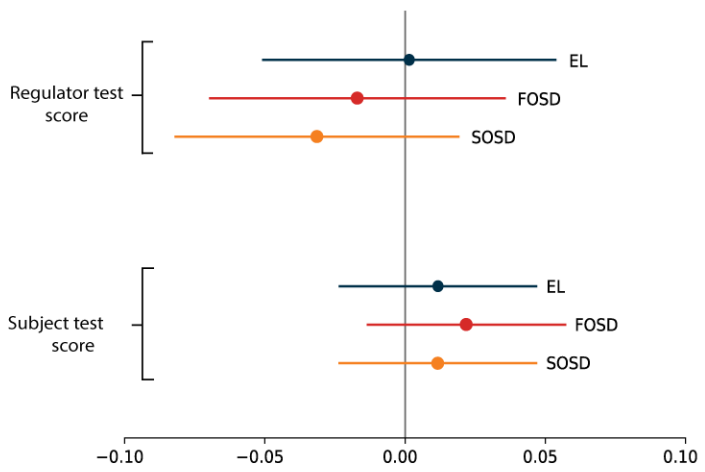

\section{Regulator quality}
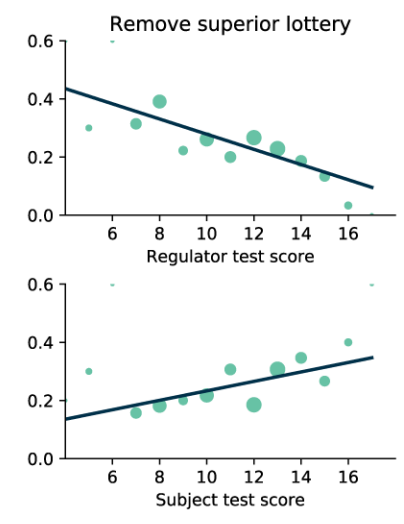

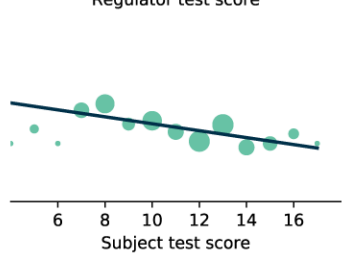

Remove inferior lottery

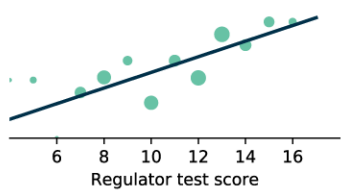

\section{Regulator intention}

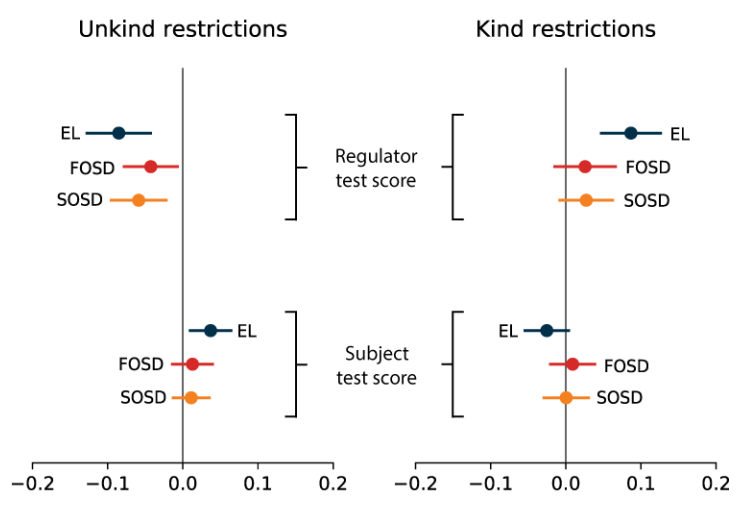

Fig. 1: Choosing to choose for others: Paternalism, competence and intentions

Notes: Lottery-choice names: EL (Expected Loss); FOSD (First-order stochastic dominance); SOSD (Second-order stochastic dominance). All error bars indicate the $95 \%$ confidence interval. Confidence intervals are calculated using standard errors clustered at the regulator level.

Plot (A) shows that on average choice regulations lower the probability, that the subject chooses the superior lottery. Plot (B) shows that test scores - and information about test scores - are not generally related to the choice of whether to restrict the choices of others. Plot (C) shows that for the EL lottery-pair, regulators are more likely to remove the superior lottery, when their own test score is lower and the subject's test score is higher and more likely to remove the inferior lottery when their own test score is higher and the subject's score is lower. Plot (D) shows that regulators with higher test scores are more likely to act in a kind fashion and less likely to act in an unkind fashion. Additionally, regulators who face a more competent subject are more likely to be unkind and less likely to be kind (for the EL choice). A restriction is defined as "kind" when the regulator removes the alternative which she did not choose for herself. A restriction is defined as "unkind" when the regulator chooses to remove the alternative which she chose for herself. 


\title{
Supplementary Materials for
}

\section{Suboptimal paternalism: Ability, benevolence, and self-selection in choosing for others}

\author{
Felix Sebastian Døssing, David Dreyer Lassen.
}

Correspondence to: $\underline{\text { ddl@econ.ku.dk }}$

\section{Contents}

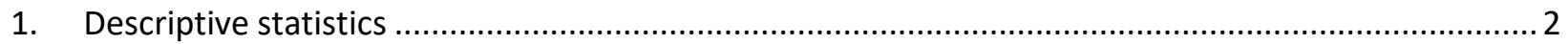

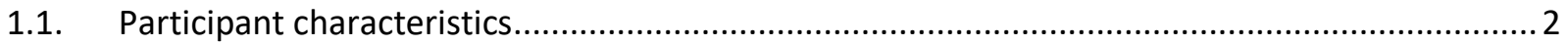

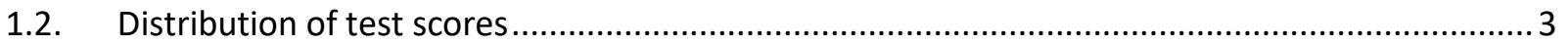

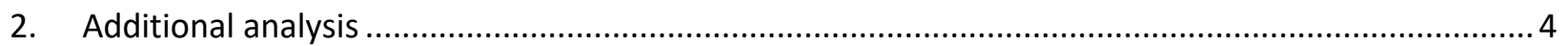

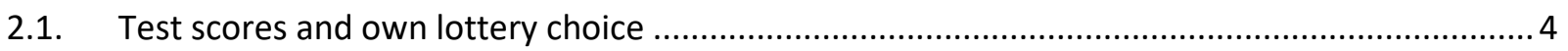

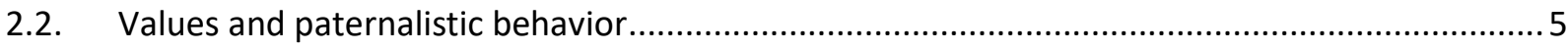

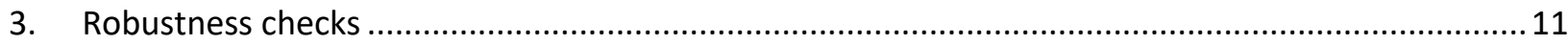

3.1. The effect of regulation on choice efficiency...................................................................... 11

3.2. Test scores and extensive margin regulation .................................................................. 13

3.3. Test scores and removing superior/inferior alternatives for EL-lottery ....................................15

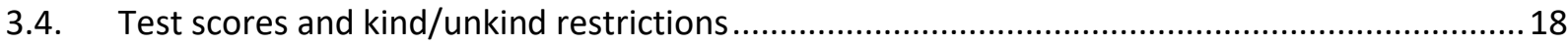

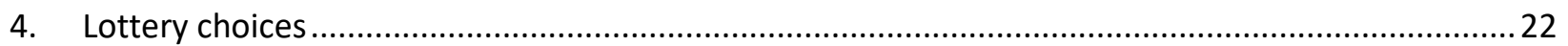

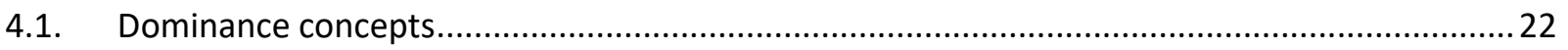

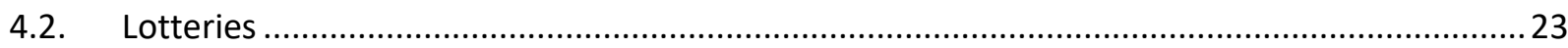

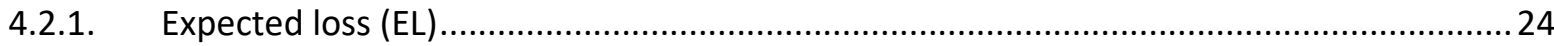

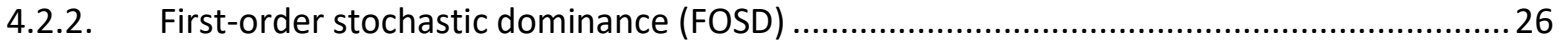

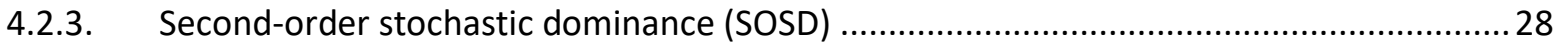

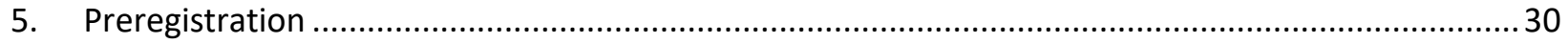

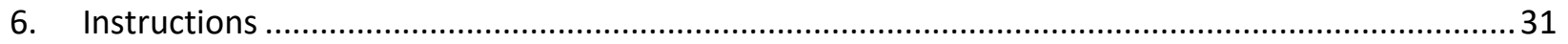

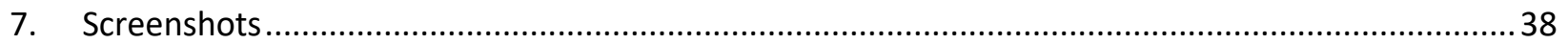

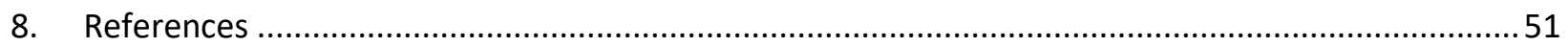




\section{Descriptive statistics}

\subsection{Participant characteristics}

Participant were drawn from a pool of volunteers at the Laboratory for Experimental Economics at the University of Copenhagen and thus consisted mostly of students. This is reflected in the distribution of participant age seen in Fig. S1. The median age in the experiment - as reported in the survey - was 24 years.

Fig. S1: Distribution of participant age

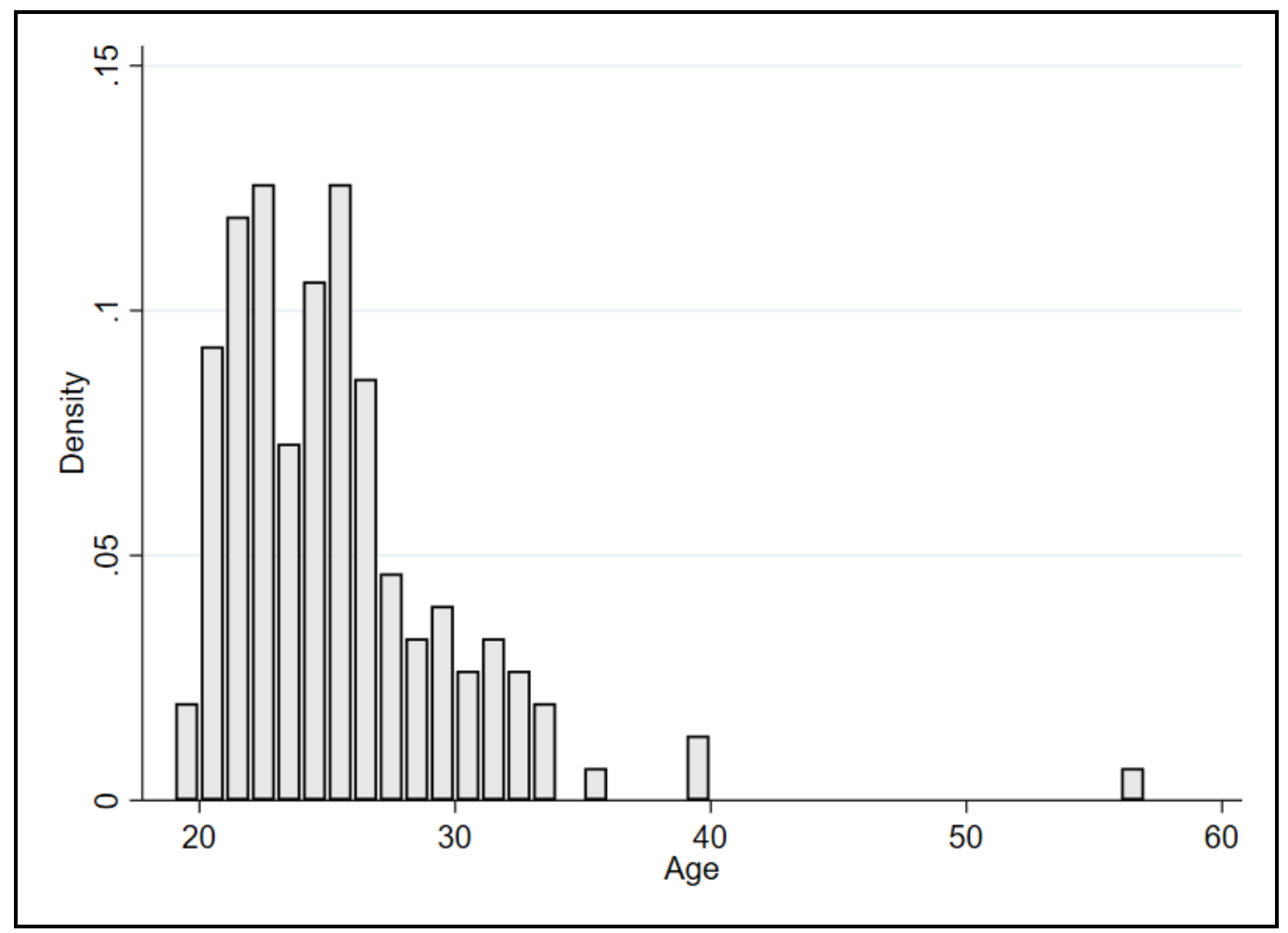

Notes: Distribution of participants age in the experiment. 71.9 pct. of the sample were between 20 and 30 years old.

In addition, gender was balanced with 41.6 pct. of the participants identifying as female in the survey. 


\subsection{Distribution of test scores}

The test featured 20 questions and the test score is defined simply as the number of correct answers.

Test scores were distributed around a mean of 11.1 correct answers, with a fair amount of variance (Fig.

S2).

Fig. S2: Distribution of test scores

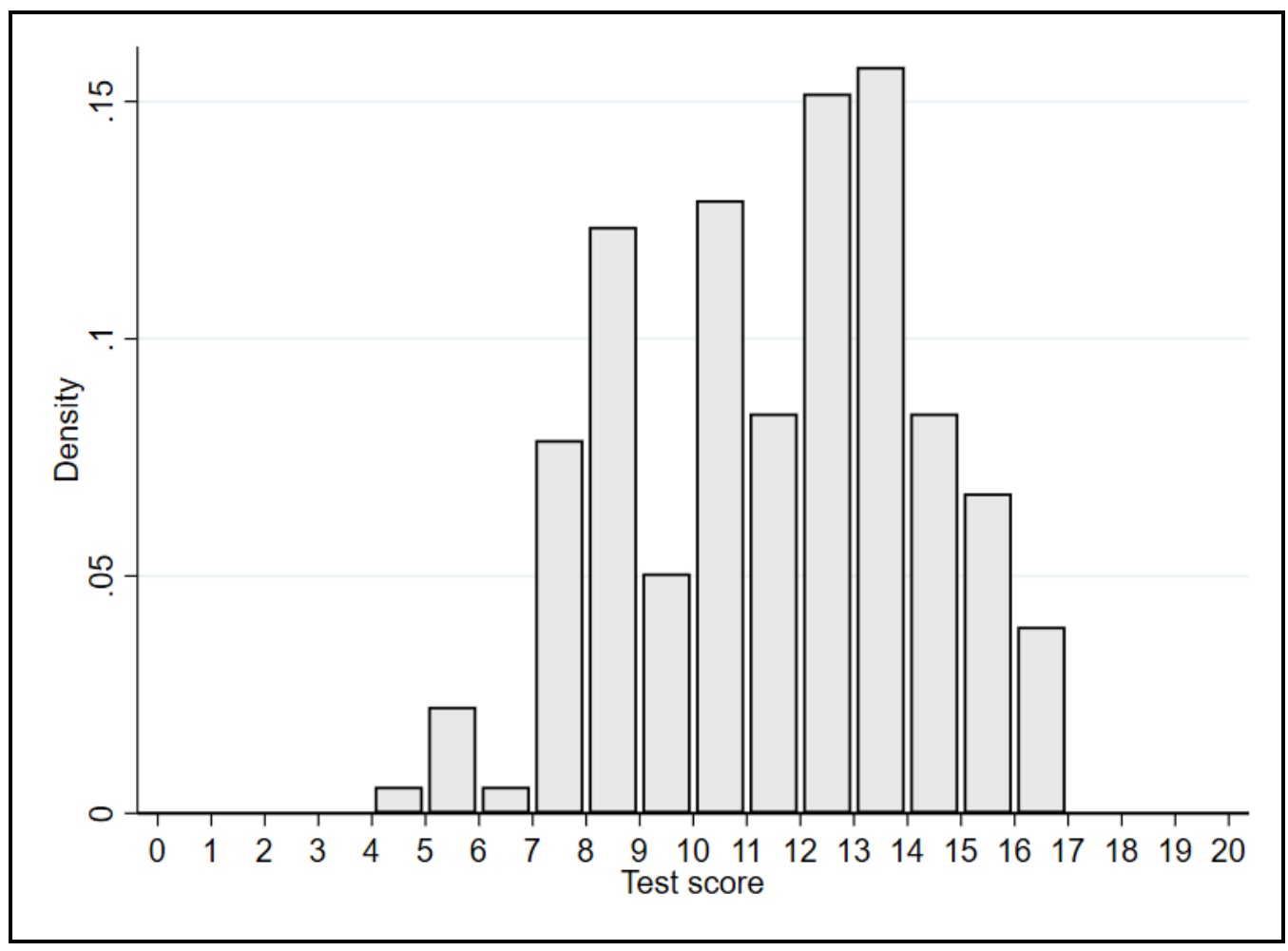

Notes: Distribution of test scores in the experiment. Participants answered 20 questions regarding probability theory and their score represents the number of correct answers.

Mean test scores differed very little between sessions, as can be seen in table S1:

Table S1: Mean test score across sessions

\begin{tabular}{lccccccc}
\hline Session & 1 & 2 & 3 & 4 & 5 & 6 & 7 \\
\hline Mean test score & 10.9 & 10.9 & 10.7 & 10.8 & 10.8 & 11.8 & 11.6 \\
& $(2.80)$ & $(2.73)$ & $(2.98)$ & $(2.82)$ & $(2.97)$ & $(2.34)$ & $(2.49)$ \\
\hline
\end{tabular}

Notes: Mean test scores for each experimental session with standard deviations in the parentheses. 


\section{Additional analysis}

\subsection{Test scores and own lottery choice}

The test score of regulators significantly predicts choosing the superior lottery for oneself for the EL $(p<0.01)$ and FOSD $(p<0.05)$ lottery pairs. Table S2 shows the coefficients from a linear probability model predicting superior lottery choice from (normalized) test scores. Numbers in parentheses show related t-statistics.

Table S2: Test scores and superior lottery choice

\begin{tabular}{llll}
\hline & EL & FOSD & SOSD \\
\hline Test score (normalized) & $0.0657^{* *}$ & $0.0699^{*}$ & -0.00753 \\
& $(3.13)$ & $(2.00)$ & $(-0.21)$ \\
$N$ & 178 & 178 & 178 \\
\hline
\end{tabular}

Notes: Test scores are significantly related to regulators choosing the superior alternative for themselves for the Expected loss lottery (EL) and the first-order stochastic dominance lottery (FOSD), but not for the second-order stochastic dominance lottery (SOSD). T-statistics are supplied in parentheses. $* * p \leq .01, * p \leq .05$.

Although test scores are in fact informative of the probability of choosing the superior lottery in the case of EL and FOSD, regulators could react to information on test scores regardless of their actual predictive value, if they think the information is of valuable. We see the fact that regulator do respond to information concerning test scores in their restriction choices as a validation of the fact that they found the information valuable. 


\subsection{Values and paternalistic behavior}

When comprehension is lower, participants seem to rely more on their political and ideological views when deciding whether to restrict the choice of the subject. We ask participants five questions about their views towards paternalistic policies and seven questions in order to identify their more general ideological stance. The paternalism questions can be seen in table S3.

Table S3: Paternalism questions

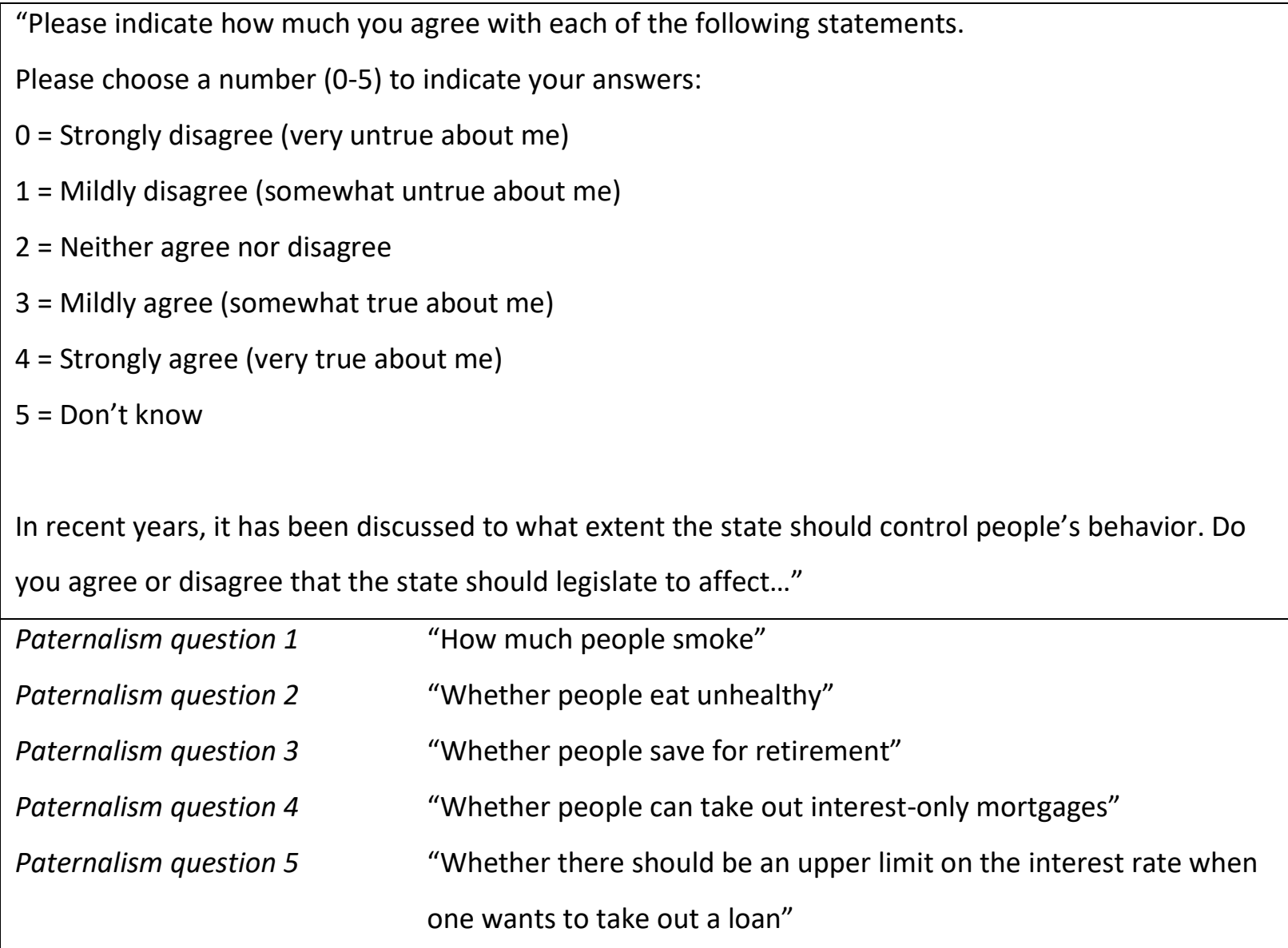

Notes: This table shows the survey questions regarding paternalistic policies. The top part of the table shows the introductory text that preceded the five questions. The bottom part of the table shows the five questions.

The spearman correlations between the answers to the five paternalism questions are positive $(p<.01)$ for all combinations. Based on the five questions we construct a new variable ("Paternalism PCA") which 
is the first principal component from a principal component analysis of the five paternalism questions. The first principal component explains 54.2 pct. of the variance.

In order to identify political ideology, we use seven questions similar to those used in the World Values Survey (Inglehart et al., 2014). The seven questions can be seen in table S4. 
Table S4: Political questions

\begin{tabular}{|c|c|c|}
\hline $\begin{array}{l}\text { Political } \\
\text { question } 1\end{array}$ & $\begin{array}{l}\text { "In political matters, people talk of } \\
\text { 'the left' and 'the right'. How } \\
\text { would you place your views on this } \\
\text { scale, generally speaking?" }\end{array}$ & $\begin{array}{l}\text { Left, } \\
2,3,4,5,6,7,8,9 \text {, } \\
\text { Right }\end{array}$ \\
\hline $\begin{array}{l}\text { Political } \\
\text { question } 2\end{array}$ & $\begin{array}{l}\text { "How would you place your views } \\
\text { on this scale?" }\end{array}$ & $\begin{array}{l}\text { Incomes should be made more equal, } \\
2,3,4,5,6,7,8,9 \text {, } \\
\text { We need larger income differences as } \\
\text { incentives for individual effort }\end{array}$ \\
\hline $\begin{array}{l}\text { Political } \\
\text { question } 3\end{array}$ & $\begin{array}{l}\text { "How would you place your views } \\
\text { on this scale?" }\end{array}$ & $\begin{array}{l}\text { Private ownership of business and industry } \\
\text { should be increased, } \\
2,3,4,5,6,7,8,9 \text {, } \\
\text { Government ownership of business and } \\
\text { industry should be increased }\end{array}$ \\
\hline $\begin{array}{l}\text { Political } \\
\text { question } 4\end{array}$ & $\begin{array}{l}\text { "How would you place your views } \\
\text { on this scale?" }\end{array}$ & $\begin{array}{l}\text { Government should take more responsibility } \\
\text { to ensure that everyone is provided for, } \\
2,3,4,5,6,7,8,9 \text {, } \\
\text { People should take more responsibility to } \\
\text { provide for themselves }\end{array}$ \\
\hline $\begin{array}{l}\text { Political } \\
\text { question } 5\end{array}$ & $\begin{array}{l}\text { "How would you place your views } \\
\text { on this scale?" }\end{array}$ & $\begin{array}{l}\text { Competition is good. It stimulates people to } \\
\text { work hard and develop new ideas, } \\
2,3,4,5,6,7,8,9 \text {, } \\
\text { Competition is harmful. It brings out the } \\
\text { worst in people }\end{array}$ \\
\hline $\begin{array}{l}\text { Political } \\
\text { question } 6\end{array}$ & $\begin{array}{l}\text { "How would you place your views } \\
\text { on this scale?" }\end{array}$ & $\begin{array}{l}\text { In the long run, hard work usually brings a } \\
\text { better life, } \\
2,3,4,5,6,7,8,9 \text {, } \\
\text { Hard work doesn't generally bring success - } \\
\text { it's more a matter of luck and connections }\end{array}$ \\
\hline $\begin{array}{l}\text { Political } \\
\text { question } 7\end{array}$ & $\begin{array}{l}\text { "How would you place your views } \\
\text { on this scale?" }\end{array}$ & $\begin{array}{l}\text { People can only get rich at the expense of } \\
\text { others, } \\
2,3,4,5,6,7,8,9 \text {, } \\
\text { Wealth can grow so there's enough for } \\
\text { everyone }\end{array}$ \\
\hline
\end{tabular}

Notes: This table presents the survey questions regarding political ideology. Questions were adapted from the World values survey (Inglehart, 2014). In the middle part of the table, we present the wording of each question and in the right part of the table, we present the scale on which participants made their answer. 
All spearman correlations between political questions are positive and generally significant (see table S5).

Table S5: Spearman correlation table (political questions)

\begin{tabular}{llllllll}
\hline & PQ1 & PQ2 & PQ3 & PQ4 & PQ5 & PQ6 & PQ7 \\
\hline PQ1 & 1.0000 & & & & & \\
PQ2 & 0.6337 & 1.0000 & & & & \\
& $(0.0000)$ & & & & & \\
PQ3 & 0.3490 & 0.4204 & 1.0000 & & & & \\
& $(0.0000)$ & $(0.0000)$ & & & & & \\
PQ4 & 0.5480 & 0.4311 & 0.3583 & 1.0000 & & & \\
& $(0.0000)$ & $(0.0000)$ & $(0.0000)$ & & & \\
PQ5 & 0.4478 & 0.4548 & 0.3943 & 0.3508 & 1.0000 & & \\
& $(0.0000)$ & $(0.0000)$ & $(0.0000)$ & $(0.0000)$ & & & \\
PQ6 & 0.2802 & 0.3639 & 0.2395 & 0.1556 & 0.4197 & 1.0000 & \\
& $(0.0005)$ & $(0.0000)$ & $(0.0030)$ & $(0.0556)$ & $(0.0000)$ & & \\
PQ7 & 0.3940 & 0.3239 & 0.1254 & 0.0945 & 0.2947 & 0.3265 & 1.0000 \\
& $(0.0000)$ & $(0.0000)$ & $(0.0963)$ & $(0.2468)$ & $(0.0002)$ & $(0.0000)$ & \\
\hline
\end{tabular}

Notes: Almost all political ideology questions are positively correlated. The table presents the Spearman's rank-order correlation for each combination of questions on political ideology with pvalues supplied in parentheses.

We construct a new variable ("Political PCA") based on the first principal component of these seven political questions. Political PCA explains 44.4 pct. of the variance and can generally be interpreted as "right-wingedness".

In Fig. S3 we plot coefficients from a linear probability model of extensive margin regulation choice on both Paternalism PCA and Political PCA. Standard errors are clustered at the regulator level. We see that the propensity of regulators to make use of their regulatory power is positively related to being in favor of paternalistic policies. This relationship is, however, only significant for the SOSD lottery-pair, which is also the lottery where comprehension is the lowest. We also see that more rightwing regulators are more likely to make use of their regulatory mandate for both the FOSD and SOSD lottery-pairs. A 
possible interpretation is that ideology becomes important when determining the better option is more difficult.

Fig. S3: Choosing to restrict by views

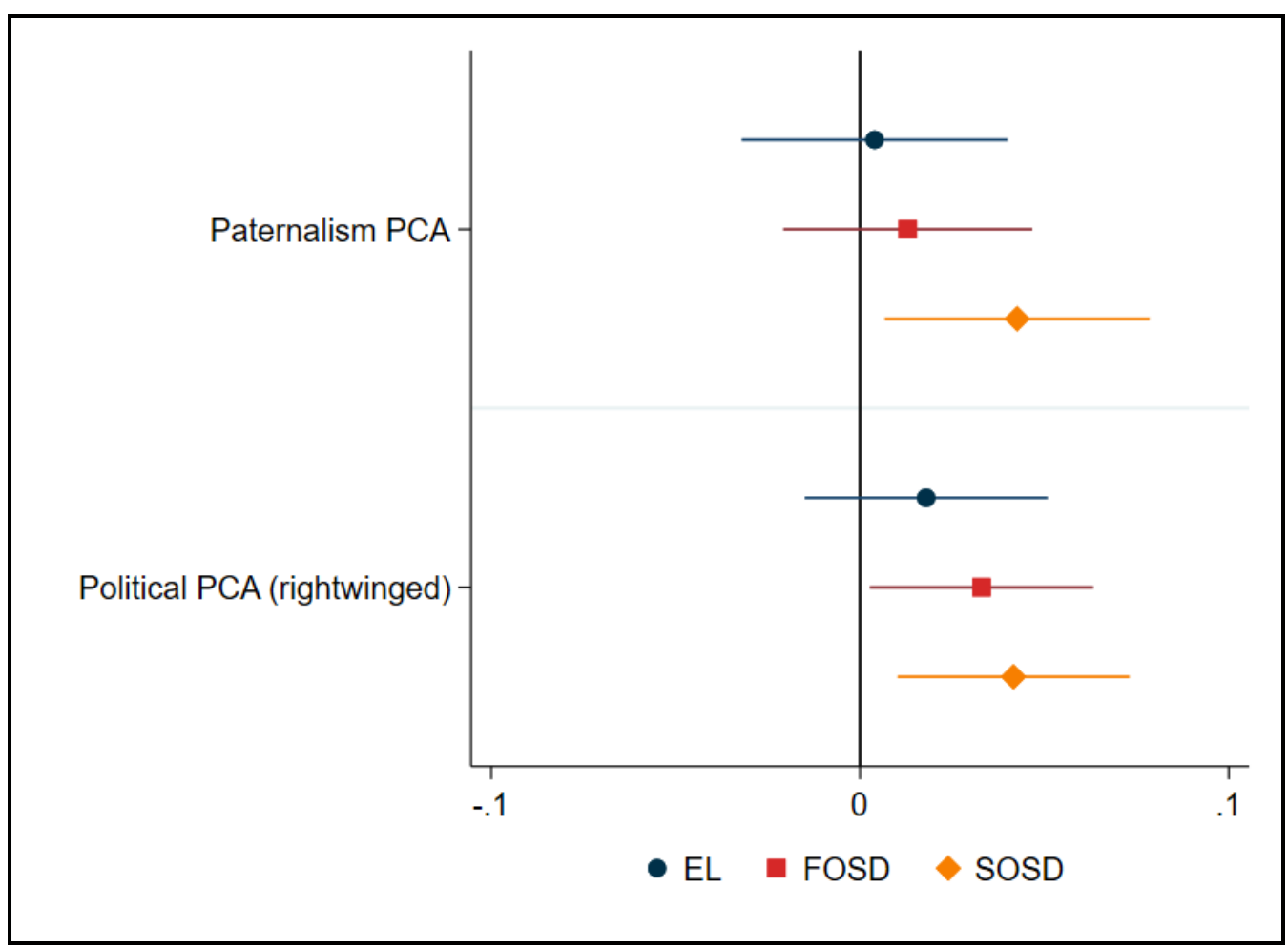

Notes: Coefficient plot from a linear regression model of the first principal component from survey questions regarding paternalistic policies and political ideology regressed on regulators choice of whether to restrict the choice of their subject. The coefficients for each principal component were estimated seperatedly using OLS and standard errors are clustered at the participant level.

Views do not seem to be connected to regulatory intention. In Fig. S4 we show coefficients of kind and unkind restrictions regressed on Paternalism PCA and Political PCA and controlled for whether the regulator chose to restrict the choice of the subject. 
Fig. S4: Kind and unkind restrictions by views

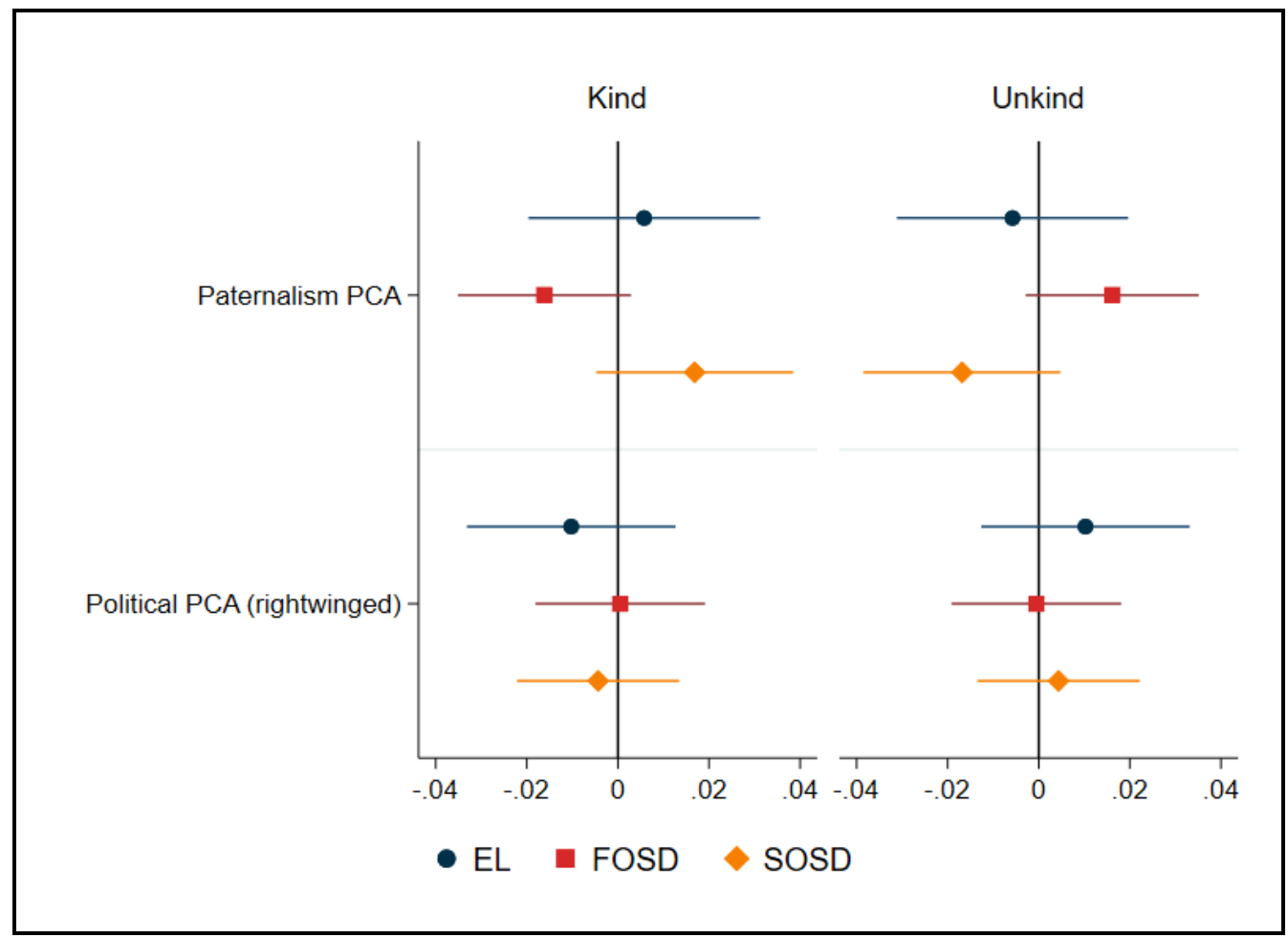

Notes: Coefficient plot from a linear regression model of the first principal component from survey questions regarding paternalistic policies and political ideology regressed on whether the regulator made a kind or an unkind restriction. A restriction is defined as "kind" when the regulator removes the alternative which she did not choose for herself. A restriction is defined as "unkind" when the regulator chooses to remove the alternative which she chose for herself. This definition is based on the assumption that regulators will choose what the consider to be optimal for themselves. The coefficients were estimated seperatedly for each PCA and each lottery choice (EL, FOSD and SOSD) using OLS and the standard errors are clusted at the participant level. 


\section{Robustness checks}

Each regulator in the experiment is matched with five other participants and decides whether and how to regulate each of these subjects. In the main text, we present results based on models that pool choices across these five interactions. In order to account for the non-independence of regulator choice, we cluster standard errors at the regulator level. Between choices, regulators were faced with feedback regarding the regulation, which they themselves were subjected to in the previous interaction. We show that the pooled estimates are generally robust to accounting for this information.

\subsection{The effect of regulation on choice efficiency}

In the leftmost column of Fig. S5, we show the estimated coefficients from a linear probability model with $95 \%$ confidence interval based on standard errors calculated using regulator-level clusters. Formally, we estimate the following model using OLS:

$$
P\left(\text { superior }_{i l}\right)=c_{l}+\beta_{l} \text { regulated }_{i l}+e_{i l}
$$

where superior $_{i l}$ is a dummy that denotes whether participant $i$ chose the dominating lottery for lottery choice I and regulated ${ }_{i l}$ is a dummy, which denotes whether choice I was a regulated or an unregulated choice. The model thus shows the effect of allowing for restrictions. We do not condition on whether the regulator chose to restrict the choice of the subject. It is clear that the coefficient is significant at the $95 \%$ level for all three lotteries $(p=.0000, p=.0013$ and $p=.0004$, respectively). In all cases subjects are significantly less likely to choose the dominating lottery when under regulation. 
Fig. 1.A in the main text plots the constant from the above model for the unregulated choice and plots the constant plus $\beta_{l}$ for the regulated choice. This is equivalent to the mean probability for each group, with standard errors clustered at the regulator level.

In the center column of Fig. S5, we estimate similar coefficients, but include a series of dummies in order to account for the information provided between choices. We estimate the following linear model using OLS:

$$
P\left(\text { superior }_{i l}\right)=c_{l}+\beta_{l} \text { regulated }_{i l}+\sum_{r=-1}^{-4}\left(\alpha_{i l r}+\alpha_{i r}+\gamma_{i l r}+\gamma_{i r}\right)+e_{i l}
$$

Here $\alpha_{i l r}$ denotes whether the regulator experienced a restricted choice for lottery I in one of the previous 4 rounds. If there was no previous round $r$, then the dummy is $0 . \alpha_{i r}$ denotes whether the regulator experienced a restricted choice for any lottery in one of the previous 4 rounds. $\gamma_{i l r}$ denotes whether the regulator experienced having the dominating lottery removed for lottery $/$ in one of the previous 4 rounds and $\gamma_{i r}$ denotes whether the regulator experienced having the dominating lottery removed for any lottery in the previous 4 rounds.

As is evident, the coefficients and their uncertainty is virtually unaffected by controlling for the information between choices. For all three lotteries, the negative effect of regulation remains significant at the $95 \%$ level $(p=.0000, p=.0013$ and $p=.0005$, respectively).

As a final robustness check, we reduce our sample to include only choices made in the first round (see the rightmost column of Fig. S5). We see that the point estimates are practically the same as those in the two other columns. However, the confidence intervals naturally become wider as the sample becomes smaller. For the EL-lottery the coefficient remains significant at the $95 \%$ level $(p=.0024)$. For the two other lotteries the confidence intervals now span zero ( $p=.153$ and $p=271$, respectively). The 
fact that the coefficients remain unchanged by limiting the sample, suggests that the difference between the leftmost and rightmost column is simply a difference in precision.

Fig. S5: Effect of regulation on choice efficiency

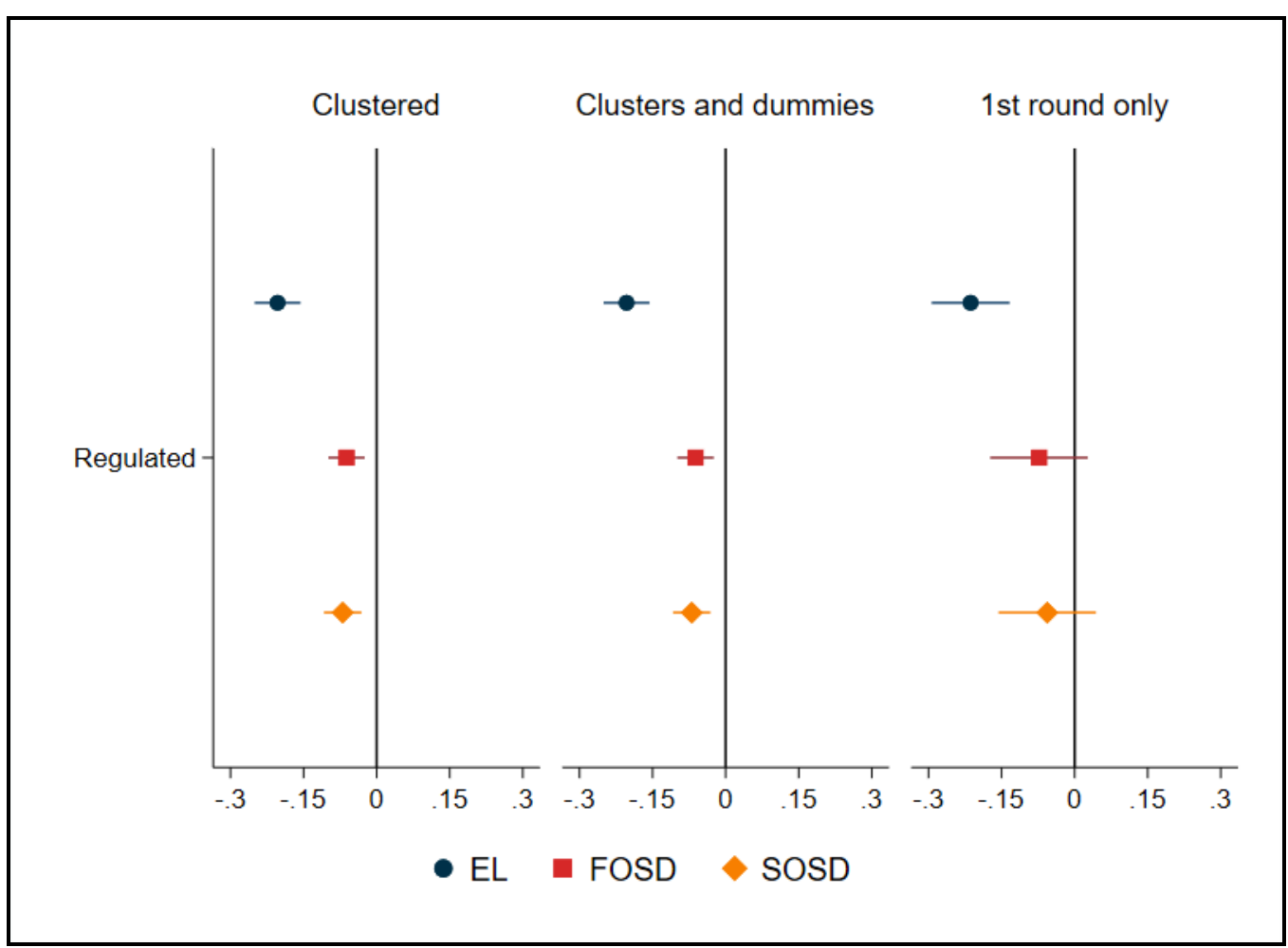

Notes: Coefficient plot from a linear regression model of the probability of subjects choosing the superior alternative regressed on a dummy for whether the choice was regulated. The regulated-dummy equals one for choices where the regulator was allowed to remove an alternative regardless of whether the regulator chose to do so. Coefficients were estimated seperatedly for each each lottery choice (EL, FOSD and SOSD) using OLS. The leftmost column shows estimates with standard errors clustered at the participant level. The center column shows estimates for when information dummies are included. The rightmost column shows estimates using only data from the first interaction.

\subsection{Test scores and extensive margin regulation}

In Fig. 1.B in the main text, we show that test scores are unrelated to the regulator's decision as to whether to restrict the choice of the subject. Here we show that this result continues to hold when we account for the information between choices. The leftmost column of the Fig. S6 reproduces Fig. 1.B in 
the main text. The variable reg_test_score is the normalized test score of the regulator and subject_test_score is the normalized test score of the subject. Formally, we estimate and plot the $\beta_{l}$ and $\delta_{l}$ coefficients from the following linear probability model using OLS:

$$
P\left(\text { restrict }_{i l}\right)=c_{l}+\beta_{l} \text { reg_test_score }_{i}+\delta_{l} \text { subject_test_score }_{i}+e_{i l}
$$

Where restrict $_{i l}$ is a dummy for whether regulator $i$ chooses to restrict his/her subject for lottery $I$. The left column of Fig. S6 shows the 95\% confidence interval, which is calculated using standard errors clustered at the regulator level. As is clear from the figure, test scores are not significantly related to extensive margin restriction choice for any of the three lotteries.

In the center column, we estimate the same linear probability model, but include dummies to control for the information received between choices. We estimate the following model using OLS:

$P\left(\right.$ restrict $\left._{i l}\right)=c_{l}+\beta_{l}$ reg_test_score $_{i}+\delta_{l}$ subject_test_score $_{i}+\sum_{r=-1}^{-4}\left(\alpha_{i l r}+\alpha_{i r}+\gamma_{i l r}+\gamma_{i r}\right)+e_{i l}$ The dummies are the same as those described in the previous section. Again we see that both the point estimates and the confidence intervals are virtually unaffected by the information dummies.

In the rightmost column, we reduce our sample to choices made in the first round and thus before any information regarding own restricted choices. The overall conclusion is the same as for the two columns on the left, except for that fact that regulators are now marginally more likely to restrict choices, when the subject has a higher test score for lottery FOSD and lottery SOSD ( $p=.058$ and $p=.078)$. 
Fig. S6: Test scores and regulation choices

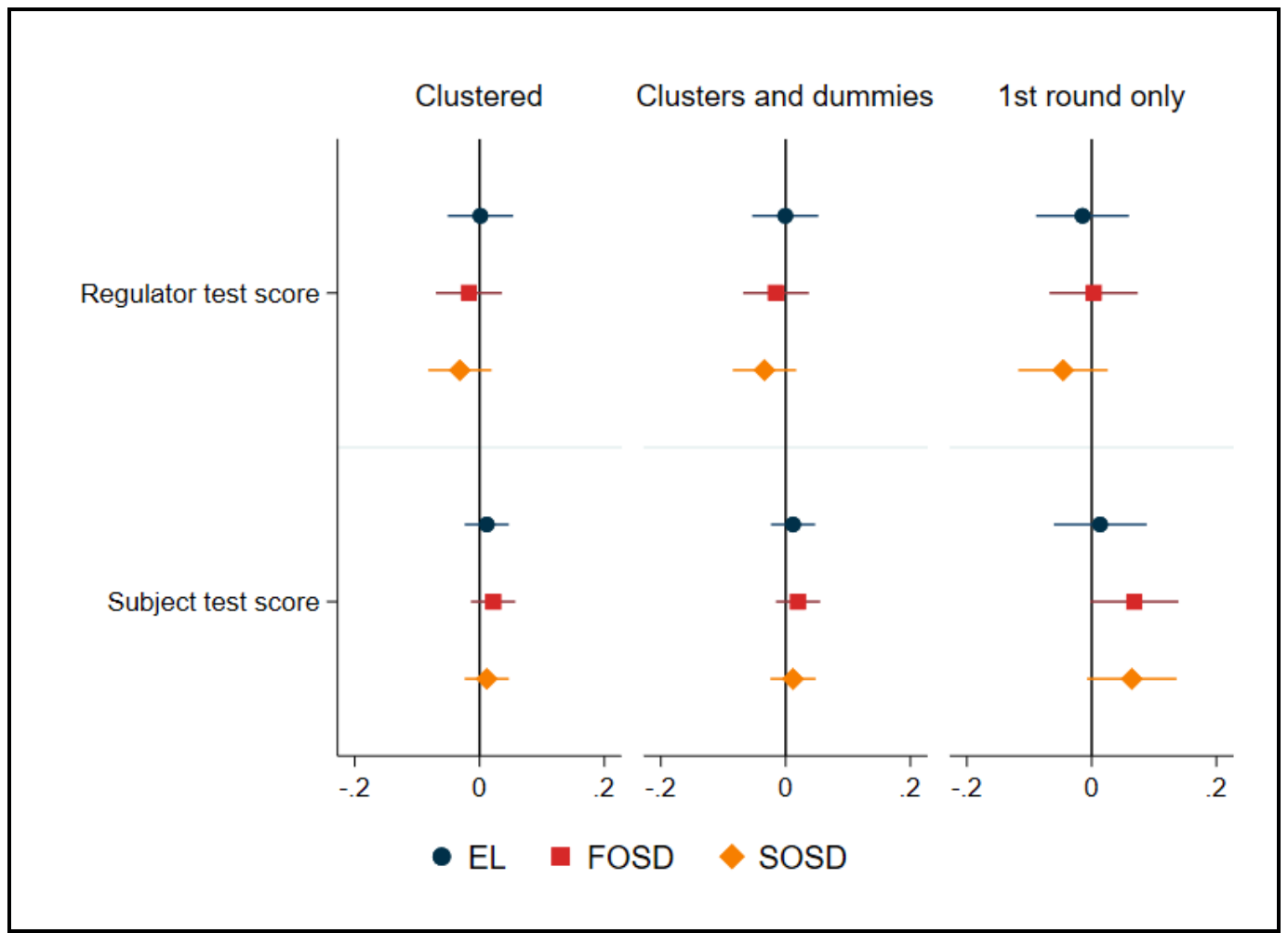

Notes: Coefficient plot from a linear regression of whether the regulators chose to restrict the choice of the subject regressed on the regulator's test score and the subject's test score. The leftmost column shows estimates with standard errors clustered at the participant level. The center column shows estimates for when information dummies are included. The rightmost column shows estimates using only data from the first interaction.

\subsection{Test scores and removing superior/inferior alternatives for EL-lottery}

In the main text, we present evidence that the choice of removing the superior and inferior lottery relates to both the regulators test score and the subject's test score for lottery EL. In Fig. 1.C in the main text, we present the binned scatterplots and regression lines for the EL lottery. As mentioned, the corresponding coefficients are generally not significant for the FOSD and SOSD lottery. This is not surprising, since comprehension is generally low for these two lotteries. We see this in Fig. $1 \mathrm{~A}$ in the main text, which shows that the probability of choosing the dominating lottery is relatively close to $50 \%$, 
which is what would be the expected level if subjects chose at random. Since subjects are unlikely to know which lottery is dominating (or even that one lottery dominates the other), they are unlikely to be able to use this to influence the subject through a restriction. In the two figures below, we see that the choice of whether to remove the superior lottery and whether to remove the inferior lottery, is indeed not significantly related to test scores for lottery FOSD and lottery SOSD, but are significantly related to both the regulator's and the subject's test score for the EL lottery.

The leftmost column of Fig. S7 shows the coefficients from an OLS estimation of the following linear probability model:

$$
P\left(\text { removesuperior }_{i l}\right)=c_{l}+\beta_{l} \text { reg_test_score }_{i}+\delta_{l} \text { subject_test_score }_{i}+e_{i l}
$$

Likewise, the leftmost column in Fig. S8 shows estimated coefficients from the following linear model:

$$
P\left(\text { removeinferior }_{i l}\right)=c_{l}+\beta_{l} \text { reg_test_score }_{i}+\delta_{l} \text { subject_test_score }_{i}+e_{i l}
$$

In both cases, we calculate the $95 \%$ confidence intervals using standard errors clustered at the regulator level. We see that for the EL lottery, the choice of removing the superior lottery is significantly negatively related to the regulator's own test score $(p=.0012)$ and significantly positively related to the subject's test score $(p=.0019)$. We also see that for the EL lottery, the choice of removing the inferior lottery is significantly positively related to the regulators own test score $(p=.0008)$ and significantly negatively related to the subject's test score $(p=.0283)$.

In the column in the middle of Fig. S7 and Fig. S8, we estimate the same models, but with added information-dummies similar to those used in the previous sections. We see that both the point estimates and the confidence intervals are as good as unchanged. 
In the rightmost column, we once again restrict our sample to include only first round choices. The coefficients point in the same direction as when we include the full sample, but the widened confidence intervals now span the zero line.

Fig. S7: Removing superior alternative

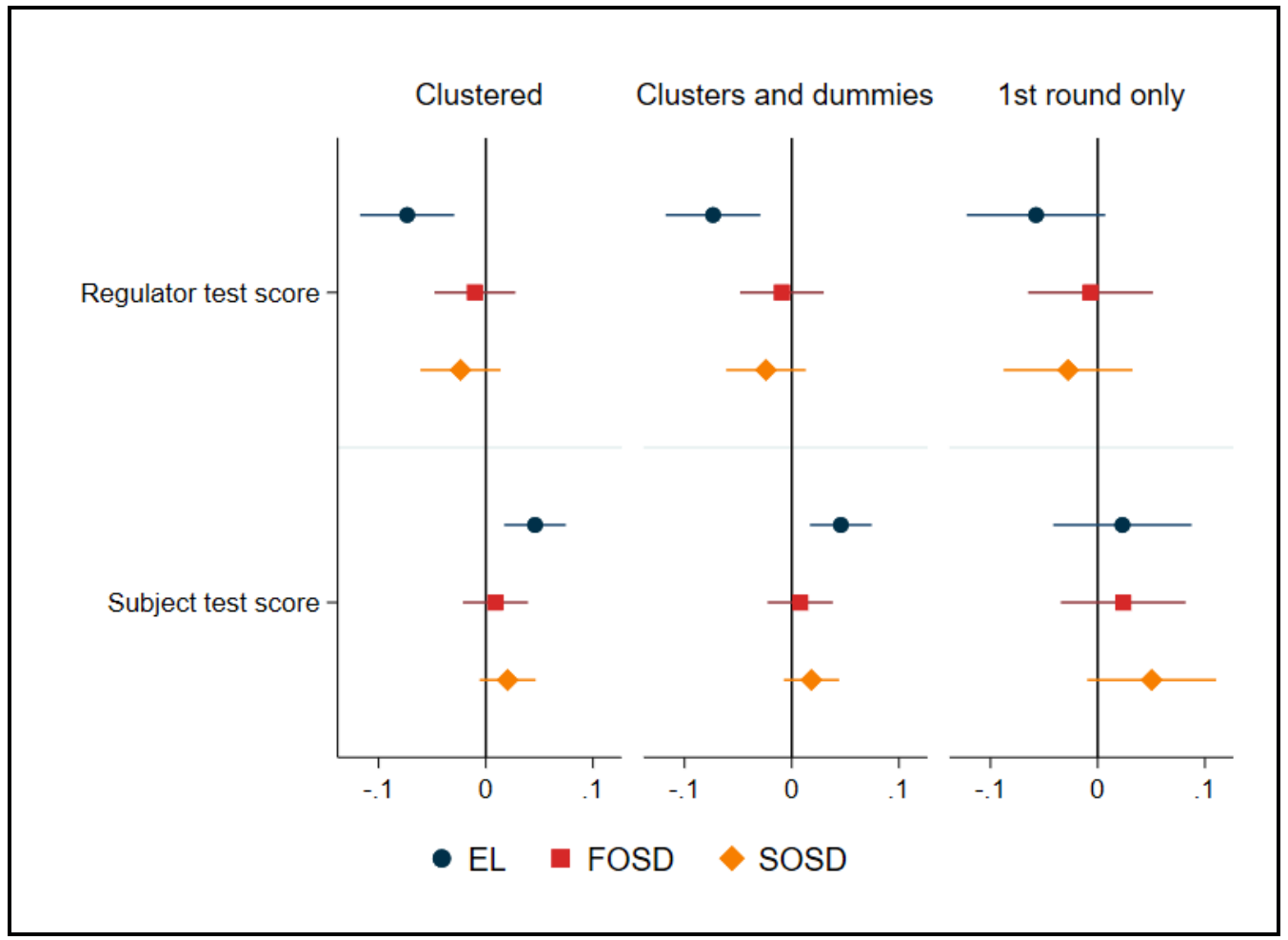

Notes: Coefficient plot from a linear regression of whether the regulator removed the superior alternative from the choice set of the subject regressed on the regulator's test score and the subject's test score. The leftmost column shows estimates with standard errors clustered at the participant level. The center column shows estimates for when information dummies are included. The rightmost column shows estimates using only data from the first interaction. 
Fig. S8: Removing inferior alternative

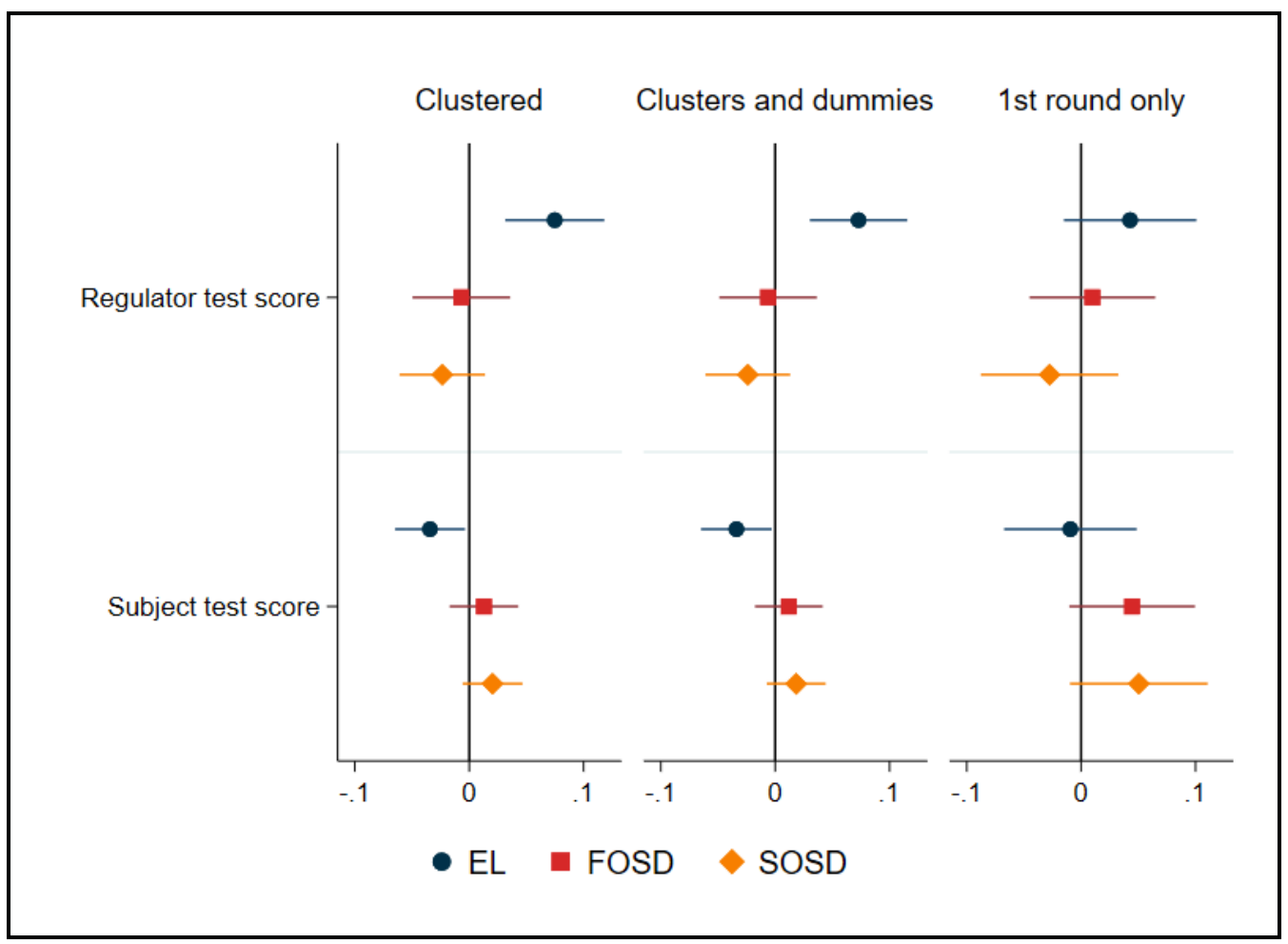

Notes: Coefficient plot from a linear regression of whether the regulator choce to remove the inferior alternative from the choice set of the subject regressed on the regulator's test score and the subject's test score. The leftmost column shows estimates with standard errors clustered at the participant level. The center column shows estimates for when information dummies are included. The rightmost column shows estimates using only data from the first interaction.

\subsection{Test scores and kind/unkind restrictions}

We now turn our attention to kind and unkind restrictions. We apply the same kind/unkind distinction as is defined in the main text. Formally, the following models are estimated using OLS:

$$
P\left(\text { unkind }_{i l}\right)=c_{l}+\beta_{l} \text { reg_test_score }_{i l}+\delta_{l} \text { subject_test_score }_{i l}+e_{i l}
$$

And

$$
P\left(\text { kind }_{i l}\right)=c_{l}+\beta_{l} \text { reg_test_score }_{i l}+\delta_{l} \text { subject_test_score }_{i l}+e_{i l}
$$


In the leftmost column of Fig. S9 and Fig. S10, we plot the coefficients for the above models with $95 \%$ confidence intervals calculated using standard errors, which are clustered at the regulator level. Own test score is significantly related to unkind restrictions for all three lotteries $(p=.0002, p=.0248$ and $p=.0028)$ and to kind restrictions for the EL lottery $(p=.0001)$. The subjects' test score is significantly related to unkind restrictions for the EL lottery $(p=.0126)$.

In the column in the middle, we add between choice information-dummies and still cluster standard errors at the regulator level. This affects neither the point estimates nor the confidence intervals.

Restricting the sample to include only first round choices has the expected effect of widening the confidence intervals. The point estimate of the effect of the subject's test score moves closer to zero for both kind and unkind restrictions for the EL lottery. For unkind restrictions, the estimate moves from 3.6 percentage points per standard deviation in subject test score to 1.0 percentage points per standard deviation in subject test score. For kind restrictions, it moves from -2.5 percentage points per standard deviation in subject test score to 0.3 percentage points per standard deviation in subject test score. The estimate of the effect of own test score on restriction type is less affected by the sample restriction. 
Fig. S9: Unkind restrictions

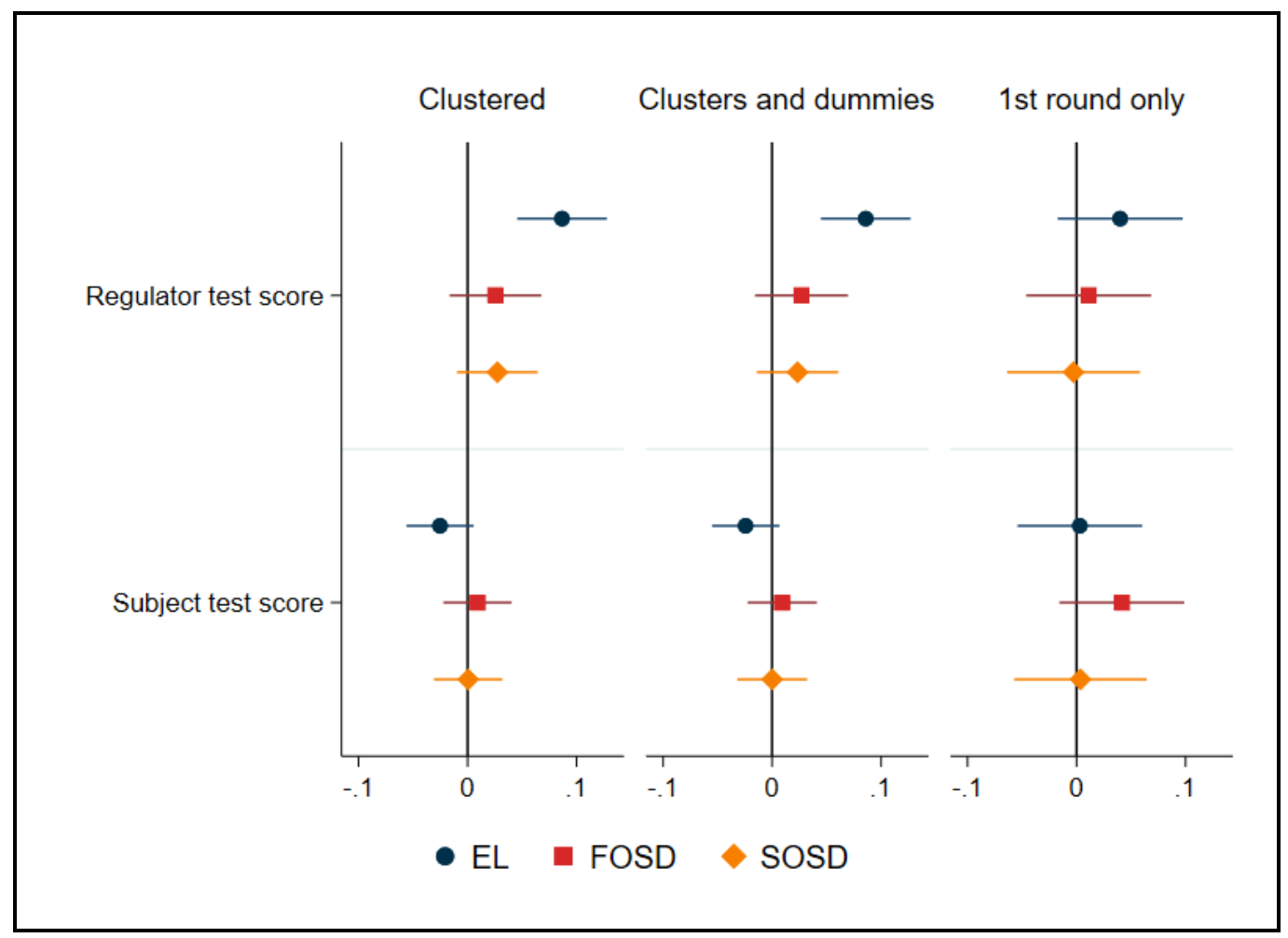

Notes: Coefficient plot from a linear regression of whether the regulator made an unkind restriction regressed on the regulator's test score and the subject's test score. The leftmost column shows estimates with standard errors clustered at the participant level. The center column shows estimates for when information dummies are included. The rightmost column shows estimates using only data from the first interaction. 
Fig. S10: Kind restrictions

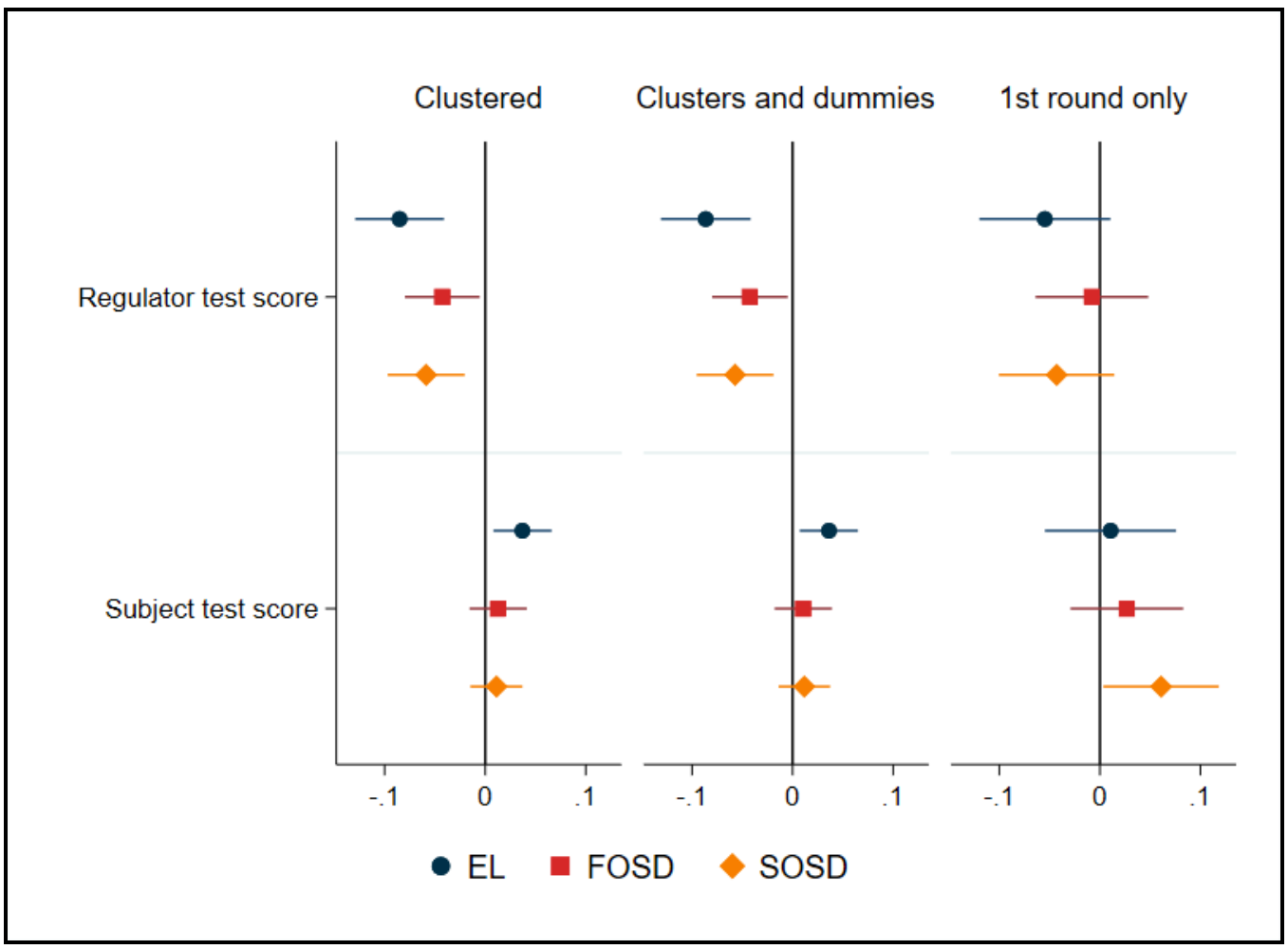

Notes: Coefficient plot from a linear regression of whether the regulator made a kind restriction regressed on the regulator's test score and the subject's test score. The leftmost column shows estimates with standard errors clustered at the participant level. The center column shows estimates for when information dummies are included. The rightmost column shows estimates using only data from the first interaction. 


\section{Lottery choices}

The experiment involved choices over four different pairs of lotteries. The fourth lottery pair has not been included in the analysis, because it did not feature any dominance relation and could therefore not be meaningfully analyzed using a superior/inferior distinction. The three analyzed lotteries were chosen to represent different concepts of stochastic dominance (Mas-Colell \& Whinston, 1995). We call the first lottery "expected loss" (EL). The EL lottery involves both a first-order stochastic dominance relation as well as the fact the inferior lottery had an expected return below one, whereas the superior lottery had an expected return above one. The "first-order stochastic dominance" (FOSD) lottery featured two lotteries, which both gave an expected payoff above one, but where one dominated the other according to first-order stochastic dominance. The "second-order stochastic dominance" (SOSD) lottery featured two lotteries, which both gave an expected payoff above one, but where one dominated the other according to the more subtle concept of second-order stochastic dominance.

In the unregulated choice, participant faced a choice between investing their endowment of 50 points in either one of the two lotteries in each lottery pair. That is, for each lottery pair they could not choose not to invest in any of the two lotteries and could not divide points between the two lotteries. We randomized the name and order of lotteries, while keeping the order constant throughout the experiment for each participant.

\subsection{Dominance concepts}

First-order stochastic dominance represents a formal specification of the idea that a distribution yields an unambiguously higher return than another distribution (Mas-Colell \& Whinston, 1995). Formally, we 
say that distribution $F(\cdot)$ first-order stochastically dominates $G(\cdot)$ if, for every nondecreasing function $u$, we have:

$$
\int u(x) d F(x) \geq \int u(x) d G(x)
$$

This is equivalent to stating that $F(\cdot) \leq G(\cdot)$ for any $x$ (where $F$ and $G$ are cumulative distribution functions).

Second-order stochastic dominance is a formal way of comparing the "riskiness" or "dispersion" of stochastic variables. Formally, we say that for any two distributions $F$ and $G$ with the same mean, $F$ second-order stochastically dominates $G$ if for every nondecreasing concave function $u$, we have:

$$
\int u(x) d F(x) \geq \int u(x) d G(x)
$$

This is equivalent to stating that $G$ is a "mean-preserving spread" of $F$. Any risk averse agent will prefer a second-order stochastically dominating distribution.

\subsection{Lotteries}

The screen above the lottery choices showed the following instructional information:

"You will make four choices over lotteries (Choice 1, Choice 2, Choice 3, Choice 4). One of these choices will be randomly selected to be your actual lottery choice. You have been given $\mathbf{5 0}$ points to invest in each lottery that you choose. At the end of the round, two regular six-sided dice (die 1 and die 2) will be thrown. Your payoff will depend on what these two dice show. This means that if Choice B is randomly chosen to be your actual choice and you choose Lottery $\mathbf{2}$ in choice B then lottery B will specify how your payoff depends on the dice." 
After this the four lottery choices where presented. A table with the following columns (except for the "name used here"-column) described each choice: "Condition", which was the condition for getting a return, "Return" which showed the return amount and "Full description", which showed a full description of the condition and the related return.

\subsubsection{Expected loss (EL)}

Table S6: Description EL

\begin{tabular}{|c|c|c|c|}
\hline Name used here & Condition & Return & Full description \\
\hline$E L 1$ & $\begin{array}{l}\text { Both dice show a } \\
\text { number below } 3\end{array}$ & SUM x INVESTMENT & $\begin{array}{l}\text { "If both dice show a } \\
\text { number below (not } \\
\text { including) } 3 \text {, then you } \\
\text { get the sum of the dice } \\
\text { times your investment." }\end{array}$ \\
\hline EL2 & $\begin{array}{l}\text { One die shows a } \\
\text { number above } 4\end{array}$ & LARGEST $x$ INVESTMENT & $\begin{array}{l}\text { "If one of the two dice } \\
\text { shows a number above } \\
\text { (not including) } 4 \text {, then } \\
\text { you get the number } \\
\text { shown by the largest of } \\
\text { the dice times your } \\
\text { investment." }\end{array}$ \\
\hline
\end{tabular}

Notes: The alternatives presented in the Expected Loss lottery-pair (EL). A similar table (excluding the leftmost column) was shown above the lottery choice in the experiment.

The expected return of lottery EL1 is 0.33 points per point invested. The expected return of lottery EL2 is 3.08 points per point invested. By plotting the cumulative distribution function for the two lotteries, we see that EL2 clearly first-order stochastically dominates EL1 (see Fig. S10). Visually we determine this by plotting the probability function for each lottery and seeing that for each possible outcome, the EL2 line is below the EL1 line. 
Fig. S10: Cumulative probability (EL-lotteries)

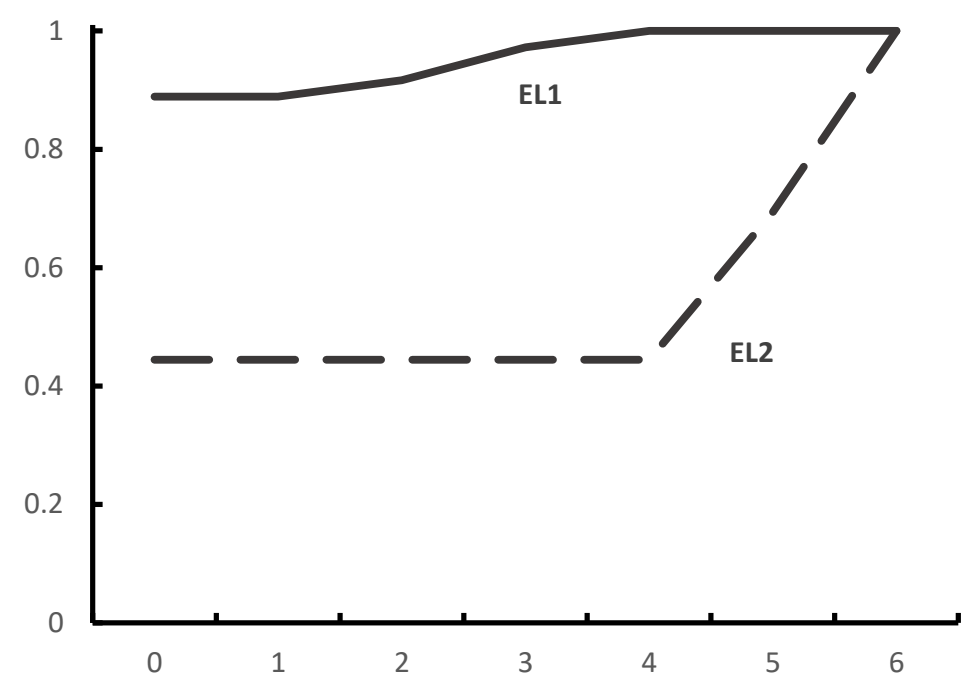

Notes: This figure plots the probability function for each of the two alternatives in the Expected Loss lottery-pair (EL). EL2 dominates EL1 according to first-order stochastic dominance. 


\subsubsection{First-order stochastic dominance (FOSD)}

Table S7: Description FOSD

\begin{tabular}{|c|c|c|c|}
\hline Name used here & Condition & Return & Full description \\
\hline FOSDI & $\begin{array}{l}\text { One die shows a } \\
\text { number above } 3\end{array}$ & SUM x INVESTMENT & $\begin{array}{l}\text { "If one of the two dice } \\
\text { shows a number above } \\
\text { (not including) 3, then } \\
\text { you get the sum of the } \\
\text { dice times your } \\
\text { investment." }\end{array}$ \\
\hline FOSD2 & $\begin{array}{l}\text { Both dice show a } \\
\text { number above } 2\end{array}$ & SUM x INVESTMENT & $\begin{array}{l}\text { "If both dice show a } \\
\text { number above (not } \\
\text { including) } 2 \text {, then you get } \\
\text { the sum of the dice times } \\
\text { your investment." }\end{array}$ \\
\hline FOSD3 & $\begin{array}{l}\text { Both dice show a } \\
\text { number below } 5\end{array}$ & SUM x INVESTMENT & $\begin{array}{l}\text { "If both dice show a } \\
\text { number below (not } \\
\text { including) } 5 \text {, then you get } \\
\text { the sum of the dice times } \\
\text { your investment." }\end{array}$ \\
\hline
\end{tabular}

Participant where randomly given a choice either between FOSD1 and FOSD3 or between FOSD2 and FOSD3. FOSD1 has an expected return of 6 points per point invested, FOSD2 has an expected return of 4 points per point invested and FOSD3 has an expected return of 2.2 points per point invested. In Fig. S11 we plot the cumulative distribution function for FOSD1, FOSD2 and FOSD3. As can be seen, there is a first-order stochastic dominance relation for each choice combination. 
Fig. S11: Cumulative probability (FOSD)

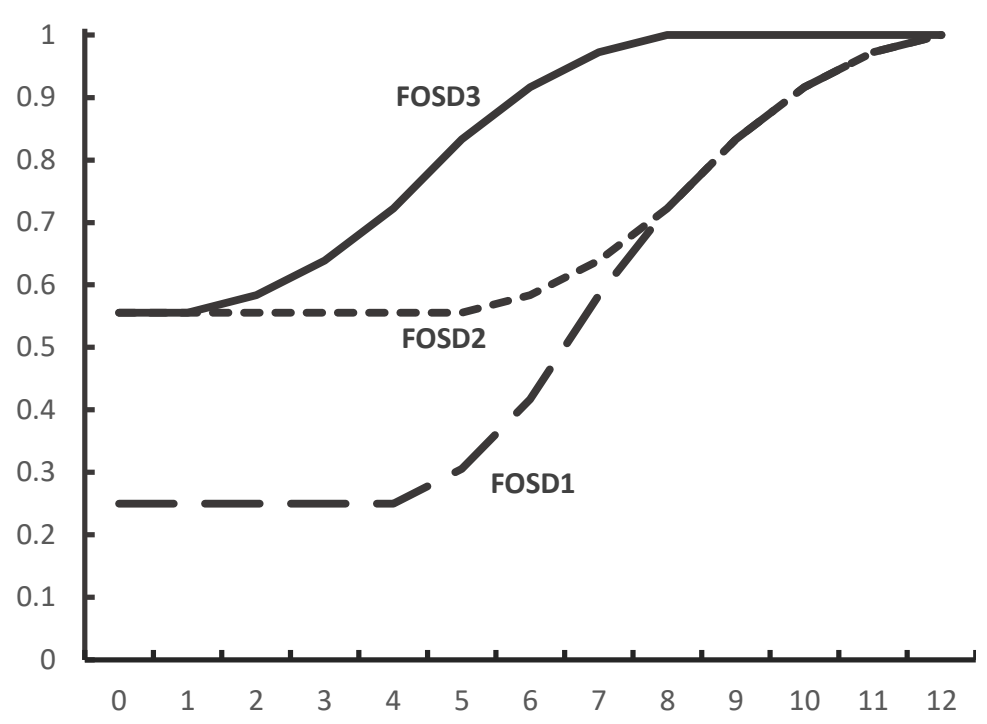

Notes: This figure plots the probability function for each of the alternatives in the first-order stochastic dominance lottery-pair (FOSD). Participant were either faced with a choice between FOSD1 and FOSD3 or between FOSD2 and FOSD3. In each case FOSD3 is first-order stochastically dominated by the other alternative. 


\subsubsection{Second-order stochastic dominance (SOSD)}

Table S8: Description SOSD

\begin{tabular}{|c|c|c|c|}
\hline Name used here & Condition & Return & Full description \\
\hline SOSD1 & $\begin{array}{l}\text { One die shows a } \\
\text { number below } 3\end{array}$ & SUM x INVESTMENT & $\begin{array}{l}\text { "If one of the two dice shows a } \\
\text { number below (not including) } \\
3 \text {, then you get the sum of the } \\
\text { dice times your investment." }\end{array}$ \\
\hline SOSD2 & $\begin{array}{l}\text { One die shows a } \\
\text { number below } 3\end{array}$ & SUM x INVESTMENT & $\begin{array}{l}\text { "If one of the two dice shows a } \\
\text { number below (not including) } \\
3 \text {, then you get the sum } \\
\text { subtracted by the number } \\
\text { shown by die } 1 \text { and added by } \\
\text { the number shown by die } 2 \\
\text { times your investment." }\end{array}$ \\
\hline
\end{tabular}

Both SOSD1 and SOSD2 give an expected return of 3 points per point invested. By looking at the cumulative distribution functions in Fig. S12, we see that SOSD2 is indeed at mean-preserving spread of SOSD1. Visually we determine this by seeing, that the area between the two lines on the left of their intersection is equivalent to the area between the two lines on the right side of their intersection. 
Fig. S12: Cumulative probability (SOSD)

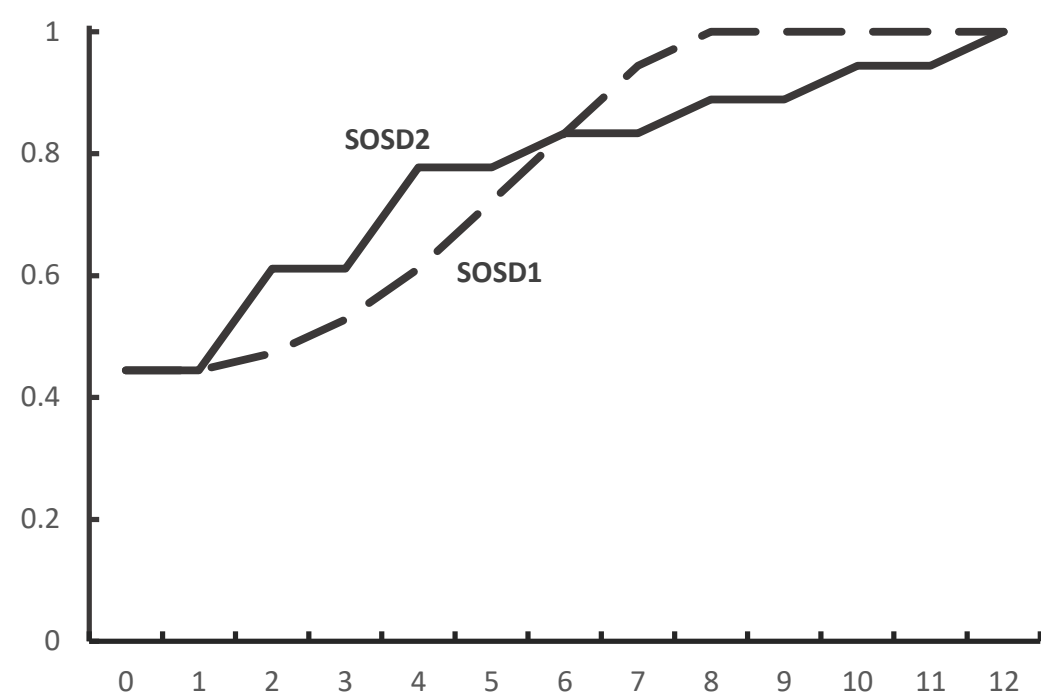

Notes: This figure plots the probability function for the two alternatives in the second-order stochastic dominance lottery-pair (SOSD). SOSD1 dominates SOSD1 according to second-order stochastic dominance. 


\section{Preregistration}

The intention to carry out the experiment was recorded on Open Science Framework on December 5,

2017. The preregistration information can be seen at https://osf.io/6vcma/wiki/home/. Since the experiment was exploratory rather than hypothesis testing, we did not register a full analysis plan. 


\section{Instructions}

\section{From instructions page:}

"In the following experiment, you will have the chance to earn money through investment in different lotteries. The experiment has two parts. First, there will be a test on your ability to calculate probabilities. Afterwards, there will be a number of choices over lotteries.

Some choices will affect yourself, while other choices will affect other participants in the experiment. The participants, which you affect with your choices, will not make choices that affect you. Each participant in the experiment is given an anonymous ID such as "Player 5 ". So if you make choices that affect Player 5, then Player 5 will not make choices that affect you.

\section{The test}

The first part of the experiment is a test of your ability to calculate probabilities. The test will take 30 minutes and features 20 questions. The test will not generally be what earns participants money in the experiment. However, one participant will be randomly selected to get 20 points for each correct answer on the test. This means that you have the potential to earn 400 points from the quiz.

\section{Test feedback}

Through the experiment, you will be shown information about the scores attained by different participants. This information will be presented in a graph such as the one in the picture below. The graph shows for each possible score, how many individuals got that score. Persons stacked on top of 
each other, represent individuals who got the same score. In the picture below, 0 participants got a score of 0-5, 2 participants got a score of 6, 2 participants got a score of 7, 6 participants got a score of 8 and so on.

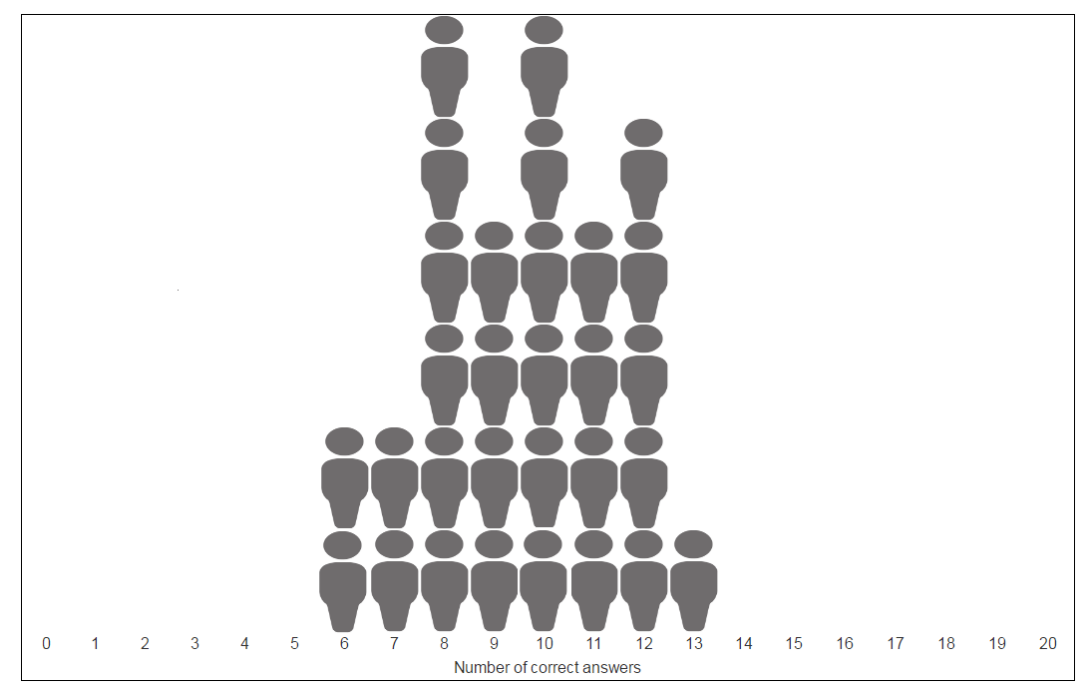

\section{The calculator}

The test as well as some of the choice screens will feature a calculator. You can access the calculator by pressing the Hide/show calculator-button in the bottom right corner of the screen. The calculator can perform addition $(+)$, subtraction $(-)$, multiplication $\left({ }^{*}\right)$ and division (/). Exponents are done with double stars $\left({ }^{* *}\right)$, so " $2^{* *} 3^{\prime \prime}$ will give you 2 raised to the power of 3 . The calculator can also return factorials. This is done by typing "fact()", so that "fact(x)" returns the factorial of $x$ (commonly written as $x$ !). If you do not know what a factorial is, then you will not need to use it.

\section{Points and money}


You will be able to earn points by investing in lotteries. Points are converted into money according to the following conversion:

1 point $=X$ DKK

\section{Help from assistants}

If you at any point during the experiment have questions, please raise your hand and a lab assistant will be there to assist you. Assistants can help with comprehension of the instructions. They are not allowed to help you with performing calculations.

\section{Ready to begin?}

When you are confident that you understand the instructions, answer the control questions and press the next-button. "

\section{Control questions on instructions page}

"Please answer the following questions. Each question is linked to the image shown above the question. You must answer each question correctly in order to continue. If you cannot answer the question please take an extra moment to think about it. If you still are not able to proceed, put up your hand and an lab assistant will come by to assist you.

Below you see a distribution of test scores. 


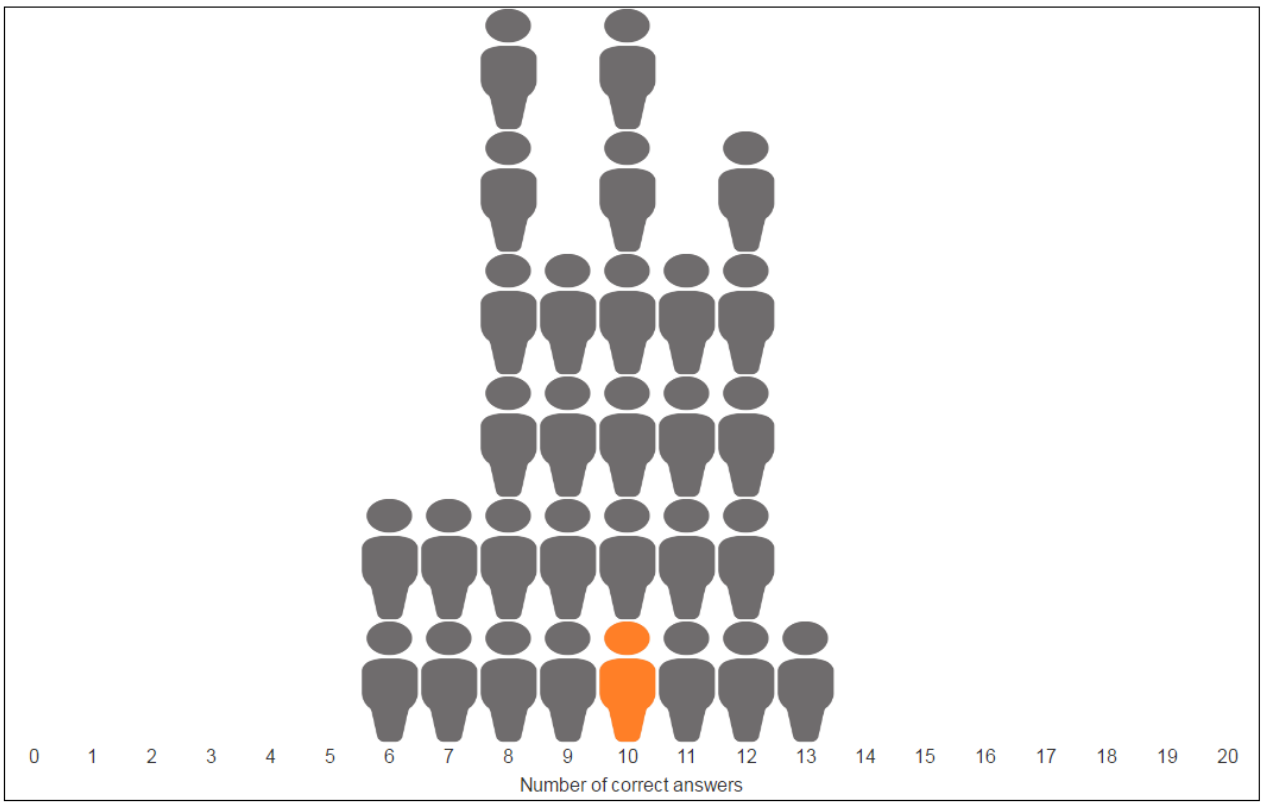

How many participants got a higher score than the orange participant?

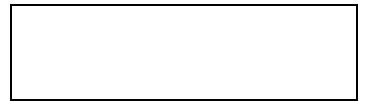

How many participants got a lower score than the orange participant?

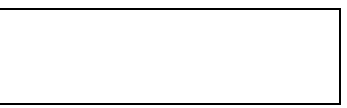

How many participants got the same score as the orange participant?

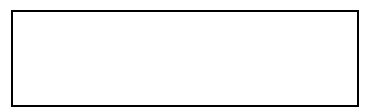

Below you see a distribution of test scores. 


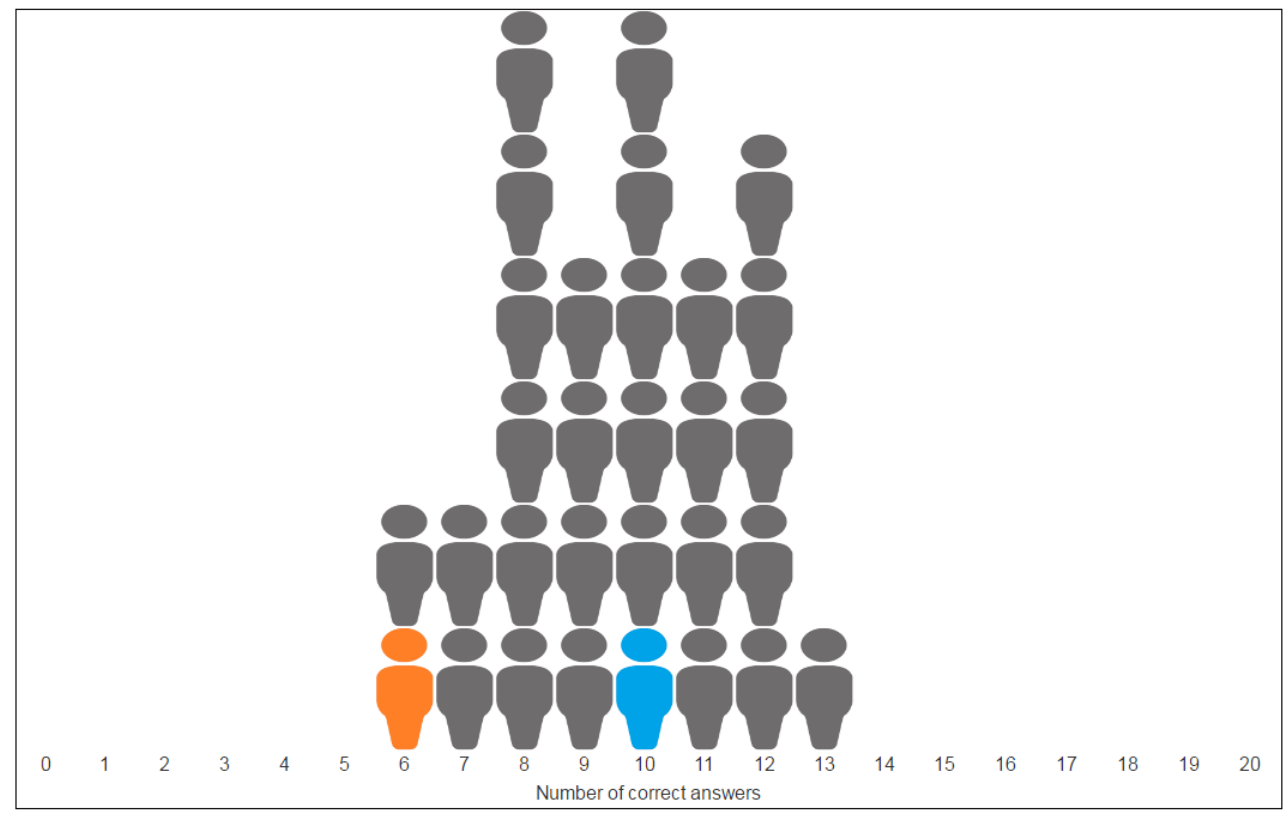

The orange participant got a higher score than the blue participant

- Yes

- No

The orange participant did worse than all other participants

- Yes

- No"

\section{Instructions from own choice screen}

"On this screen you will make choices that affect yourself. 
You will make four choices over lotteries (Choice 1, Choice 2, Choice 3, Choice 4). One of these choices will be randomly selected to be your actual lottery choice. You have been given $\mathbf{X}$ points to invest in each lottery that you choose. At the end of the round, two regular six-sided dice (die 1 and die 2) will be thrown.

Your payoff will depend on what these two dice show. This means that if choice $\mathbf{B}$ is randomly chosen to be your actual lottery choice and you choose Lottery $\mathbf{2}$ in choice $\mathbf{B}$ then lottery 2 will specify how your payoff depends on the dice.

Below you see information regarding your own score in the test.

\section{Number of questions: 20}

Your score: $\mathbf{X}$

Player X's score: $\mathbf{X}$

In the picture below it is shown for each possible score, how many participants got that score.

Individuals on top of each other got the same score. The blue participant is you.

$$
\text { [Histogram of test scores]" }
$$

\section{Instructions from regulation choice screen}

"On this screen you will make choices that affect Player $\mathbf{X}$.

Player $\mathrm{X}$ will make four choices over lotteries. These are the same choices as those [if not first round: you made on the previous screen (and the same lotteries)] [else: you have seen on previous screens]. 
One of the choices will be randomly selected to be his/her actual lottery choice. Player $\mathrm{X}$ has been given $\mathrm{X}$ points to invest in each lottery.

If you wish, you may remove lotteries, so that Player $\mathrm{X}$ will be unable to choose those lotteries. Note that Player $\mathrm{X}$ will not make any choices that affect you in this experiment.

Below you see information regarding your own score, as well as Player X's score in the test.

\section{Number of questions: 20}

\section{Your score: $\mathbf{X}$}

\section{Player X's score: X}

In the picture below it is shown for each possible score, how many participants got that score.

Individuals on top of each other got the same score. The blue participant is you. The orange participant is Player $\mathrm{X}$.

[Histogram of test scores]" 


\section{Screenshots}

\section{Instructions}

\section{Introduction}

In the following experiment, you will have the chance to earn money through investment in different lotteries. The experiment has two parts. First, there will be a test on your ability to calculate probabilities. Afterwards, there will be a number of choices over lotteries.

Some choices will affect yourself, while other choices will affect other participants in the experiment. The participants, which you affect with your choices, will not make choices that affect you. Each participant in the experiment is given an anonymous ID such as "Player 5 ". So if you make choices that affect Player 5 , then Player 5 will not make choices that affect you.

\section{The test}

The first part of the experiment is a test of your ability to calculate probabilities. The test will take 30 minutes and features 20 questions. The test will not generally be what earns participants money in the experiment. However, one participant will be randomly selected to get 20 points for each correct answer on the test. This means that you have the potential to earn 400 points from the quiz.

\section{Test feedback}

Through the experiment, you will be shown information about the scores attained by different participants. This information will be presented in a graph such as the one in the picture below. The graph shows for each possible score, how many individuals got that score. Persons stacked on top of each other, represent individuals who got the same score. In the picture below, 0 participants got a score of 0-5,2 participants got a score of 6,2 participants got a score of 7, 6 participants got a score of 8 and so on.

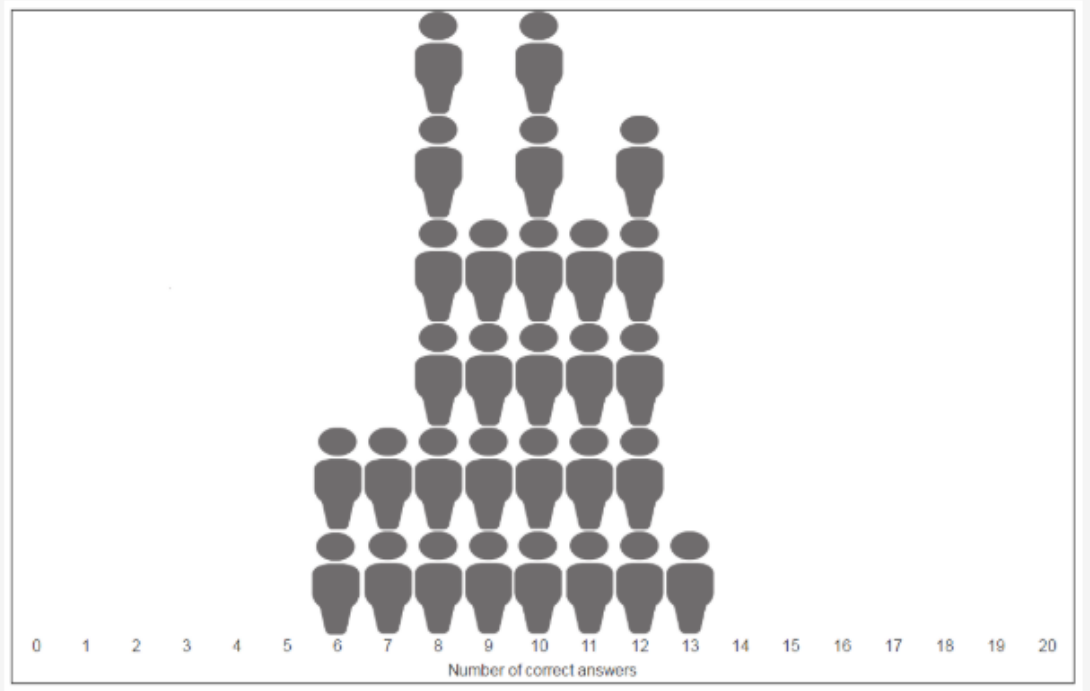

\section{The calculator}

The test as well as some of the choice screens will feature a calculator. You can access the calculator by pressing the Hide/show calculator-button in the bottom right corner of the screen. The calculator can perform addition $(+)$, subtraction $(-)$,

multiplication $\left({ }^{*}\right)$ and division (). Exponents are done with double stars $\left({ }^{* *}\right)$, so $2^{* x} 3^{*}$ will give you 2 raised to the power of 3. The calculator can also retum factorials. This is done by typing "facto", so that "fact( $(x)$ " returns the factorial of $x$ (commonly written as $\mathrm{x}$ !). If you do not know what a factorial is, then you will not need to use it.

\section{Points and money}

You will be able to earn points by investing in lotteries. Points are converted into money according to the following conversion: 1 point $=0.2 \mathrm{DKK}$

\section{Help from assistants}

If you at any point during the experiment have questions, please raise your hand and a lab assistant will be there to assist you. Assistants can help with comprehension of the instructions. They are not allowed to help you with performing calculations.

\section{Ready to begin?}

When you are confident that you understand the instructions, answer the control questions and press the next-button. 


\section{Control questions}

Please answer the following questions. Each question is linked to the image shown above the question. You must answer each

question correctly in order to continue. If you cannot answer the question please take an extra moment to think about it. If you still are not able to proceed, put up your hand and an lab assistant will come by to assist you.

Below you see a distribution of test scores.

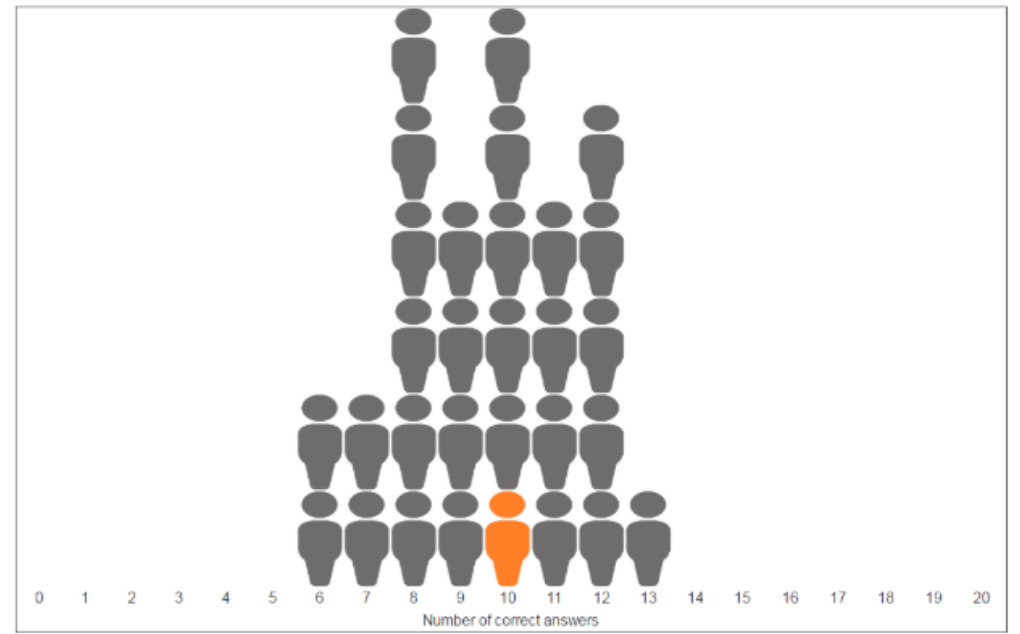

How many participants got a higher score than the orange participant?

How many participants got a lower score than the orange participant?

How many participants got the same score as the orange participant?

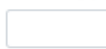

The orange participant's score was above average:

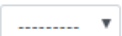

Below you see a distribution of test scores.

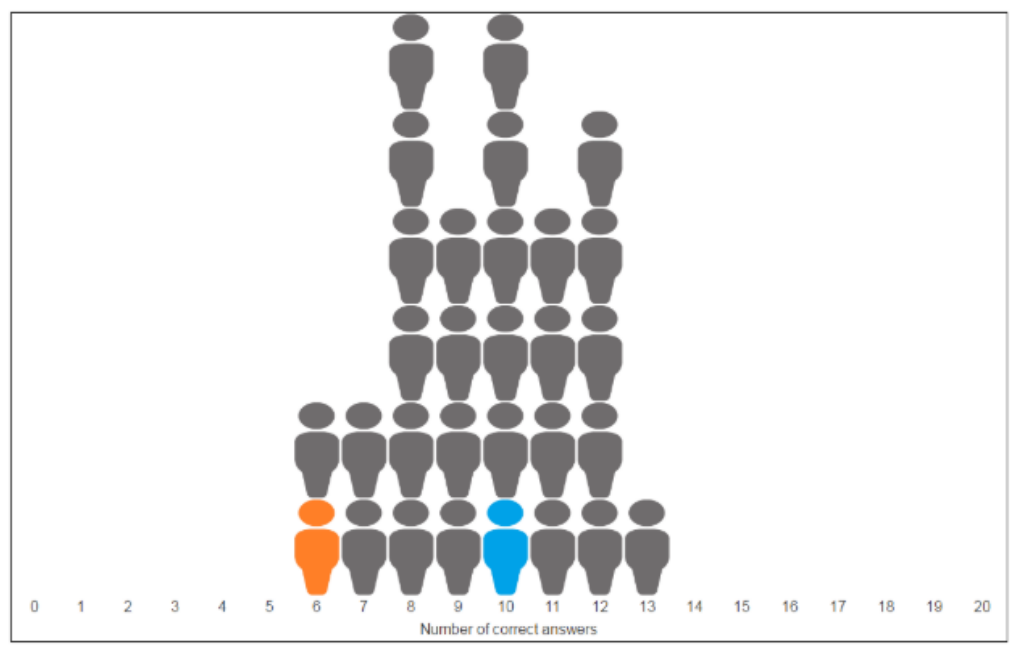

The orange participant got a higher score than the blue participant:

…….

The orange participant did worse than all other participants:

......... 
Test

Time left to complete this page: 29:53

Please answer the following questions as best as possible

Which of the following is equal to $25 \%$ ?

- $1 / 5$

$\circ 0.30$

- $1 / 25$

- $1 / 4$

- $25 / 50$

2

You throw a coin with two sides ('side A' and 'side B'). There is an equal chance of it landing on either of the two sides. What is the probability that the coin lands on side $A$ ?

$\circ 1 / 3$

$\circ 2$

$\circ 1 / 2$

- $1 / 4$

$\circ 1$

You throw a fair die with six sides. What is the probability that it lands on 4 ?

$\circ 4$

० $3 / 6$

$\circ 2 / 3$

- $1 / 4$

- $1 / 6$

You draw a card from a regular set of playing card ( 52 cards). What is the probability of drawing a picture card (there are 3 picture cards for each of the 4 colors):

- $3 / 13$

$03 / 52$

० $3 / 52$

- $12 / 13$

$\circ 1 / 6$

Lisa, Jim, Andreas and Caroline play a game where one of them will win. Which of the following could be a valid representation of their chances of winning?

- Lisa (20\%), Jim (40\%), Andreas (-10\%), Caroline (50\%)

- Lisa (10\%), Jim (20\%), Andreas (40\%), Caroline (10\%)

- Lisa (30\%), Jim (30\%), Andreas (30\%), Caroline (30\%)

- Lisa (0\%), Jim (25\%), Andreas (40\%), Caroline (35\%)

- Lisa (20\%), Jim (30\%), Andreas (0\%), Caroline (0\%)

The probability that Sarah will get a job within the next week is $65 \%$. What is the probability that Sarah will not get a job within the

next week?

- $35 \%$

- $65 \%$

- $25 \%$

- $65 \%$

○ $50 \%$

You throw a fair coin with the two sides marked 'A' and ' $B$ '. You throw the coin until it lands on ' $B$ '. What is the probability that you will throw the coin no more than 4 times?

- $12 / 15$

$\circ 3 / 2$

$\circ 15 / 16$

0 $62 / 64$

You throw two regular fair-sided dice. What is the probability that both land on either 1 or 2?

० $1 / 3$

- $1 / 6$

- $3 / 8$

( $1 / 9$

$\circ 1 / 2$ 
In a town $80 \%$ of the population owns a car. $25 \%$ of these cars are black. What is the probability that a random citizen in the town owns a black car?

- $10 \%$

$\circ 25 \%$

- $20 \%$

- $50 \%$

- $80 \%$

11

An alarm goes off every hour. You arrive at a random time and wait for 10 minutes. What is the probability that you will hear the alarm go off?

$1 / 5$

- $1 / 20$

- $1 / 4$

- $1 / 3$

$\circ 1 / 6$

12

You are buying a new car. You may choose either black, white, blue or red as the color. You can choose a large or a small car and you may choose to put in a sunroof or not. If you pick each feature at random, what is the probability that you end up with a small black car with a sunroof?

- $12.8 \%$

० $1 / 4$

- $6.25 \%$

- $1 / 25$

- $5 \%$

13

There is a bag with one blue, one red, one green, and one yell ow chip in it. There are no other chips in the bag. You draw the chips from the bag in a random order without putting them back in the bag. What is the probability of drawing first the blue, then the red, then the yellow and then the green chip in that excact sequence?

$0.1 / 4$

- $5 \%$

0 $1 / 20$

- $1 / 24$

○ $100 \%$

14

You have 8 quests of which three are children. If you place your guests randomly on the 8 available seats, which are placed in a circle, what is the probability that the three children will end up sitting next to each other?

- About $15 \%$

- About $9.5 \%$

- About 23.5\%

- About $30 \%$

- About $67 \%$

15

A basketball player is about to throw two shots at the goal. On the first shot he has an $80 \%$ chance of scoring. On the second shot $h$ has an $85 \%$ chance of scoring, if he scored on the first shot, and a $70 \%$ chance of scoring if he didn't score on the first shot. What is the chance that he will score on at least one of the two shots?

$65 \%$

- $6 \%$

- $87 \%$

- $10 \%$

- $94 \%$

You have gambled on three different football matches. The first gamble will earn you 20 points and has a $55 \%$ chance of going through. The second gamble will earn you 10 points and has a $40 \%$ chance of going through. The third gamble will eam you 15 points and has a $15 \%$ chance of going through. What is your expected retum from this ticket?

- 17.25 points

- 20 points

- 45.5 points

- 3.3 points

10 points

17

In a town $20 \%$ of the citizens wear hats. $15 \%$ of the citizens are funny. Among the funny citizens $50 \%$ wear hats. What is the probability that a citizen who is wearing a hat is funny?

○ $25 \%$

- $33.5 \%$

- $55 \%$

- $37.5 \%$

○ $51.2 \%$ 
In a town $20 \%$ of the citizens wear hats. $15 \%$ of the citizens are funny. Among the funny citizens $50 \%$ wear hats. What is the probability that a citizen who is wearing a hat is funny?
- $25 \%$
- $33.5 \%$
- $55 \%$
- $37.5 \%$
- $51.2 \%$

18

You have a sandwich shop. Off all your customers $70 \%$ choose the chicken sandwich and $30 \%$ choose the vegetarian sandwich. What is the probability that 7 of the next 10 customers will choose the chicken sandwich?
$100 \%$
- About $27 \%$
$50 \%$
About $35 \%$
About $95 \%$

19

You choose 4 scoops of ice cream. There are 6 different flavours available. You can choose any flavour as many times as you like, as long as you end up with excactly 4 scoops. How many different 4 scoop-ice cream combinations can y-
210
122
20015
84
10

20

You throw a regular fair sided die four times. What is the probability that you throw at least two two

About $22.5 \%$

About $13.2 \%$

- $50 \%$

- About $67 \%$

- $23 \%$

Please wait for the time to run out.

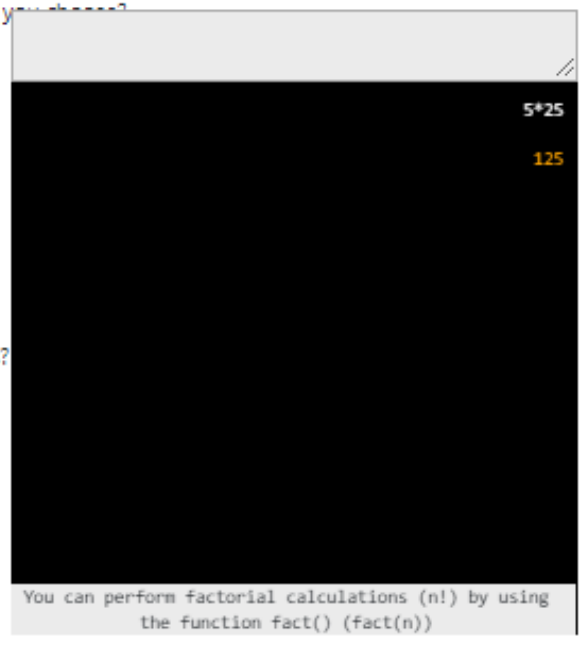




\section{Test score guess}

Below you see how the test scores of the participants in the experiment are distributed. Please click on the number of correct answers that you think you got in the test.

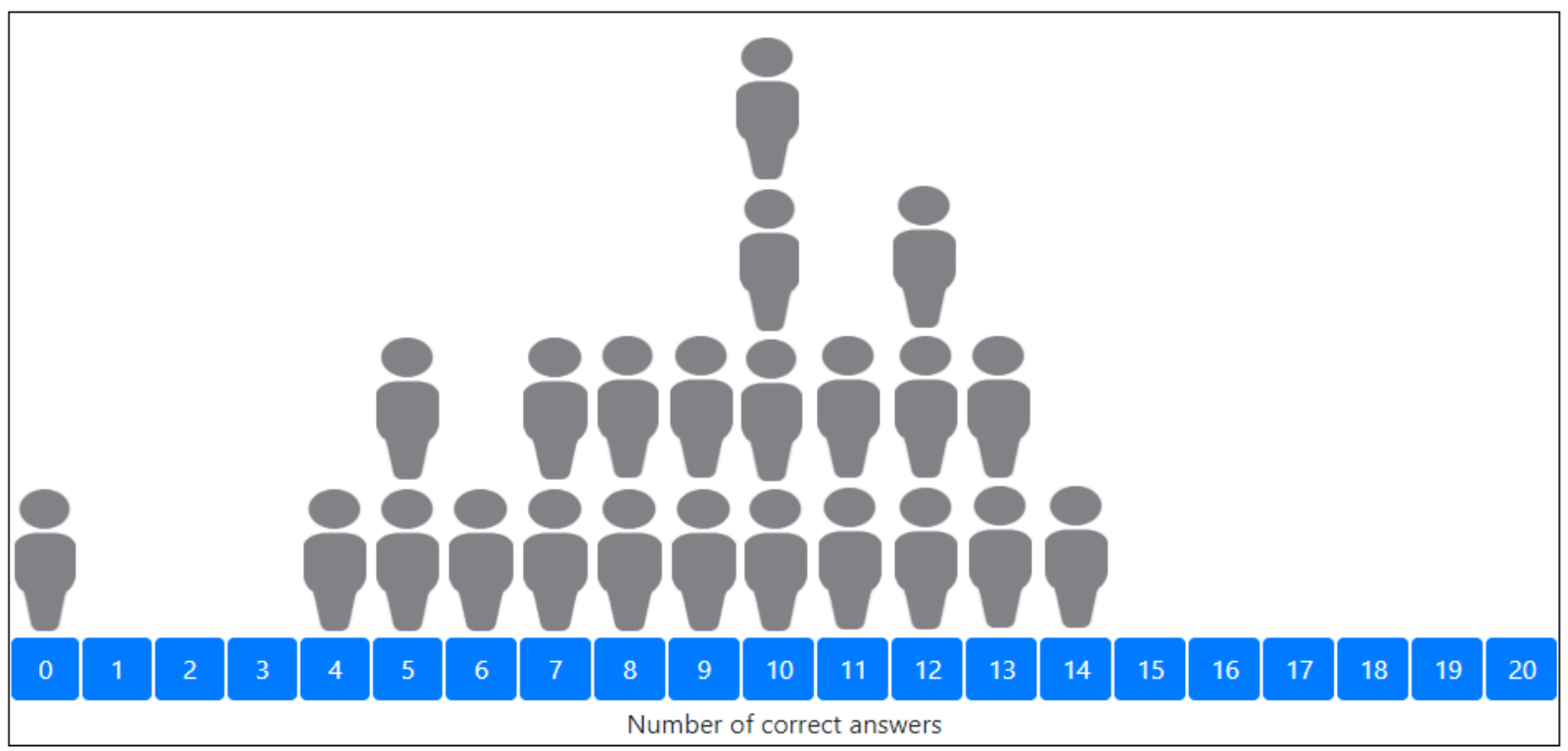




\section{Lottery choice}

On this screen you will make choices that affect yourself.

You will make four choices over lotteries (Choice 1, Choice 2, Choice 3, Choice 4). One of these choices will be randomly selected to be your actual lottery choice. You have been given $\mathbf{5 0}$ points to invest in each lottery that you choose. At the end of the round, two regular six-sided dice (die 1 and die 2) will be thrown. Your payoff will depend on what these two dice show. This means that if choice $\mathbf{B}$ is randomly chosen to be your actual lottery choice and you choose Lottery $\mathbf{2}$ in choice $\mathbf{B}$ then

lottery B will specify how your payoff depends on the dice.

\section{Choice 1}

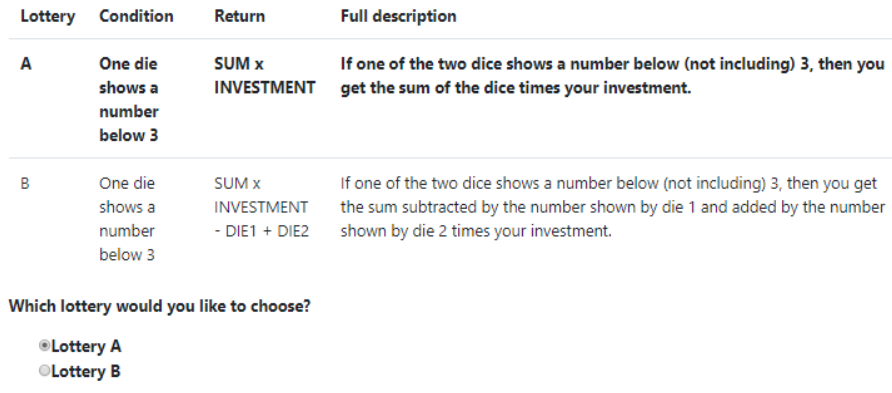

\section{Choice 2}

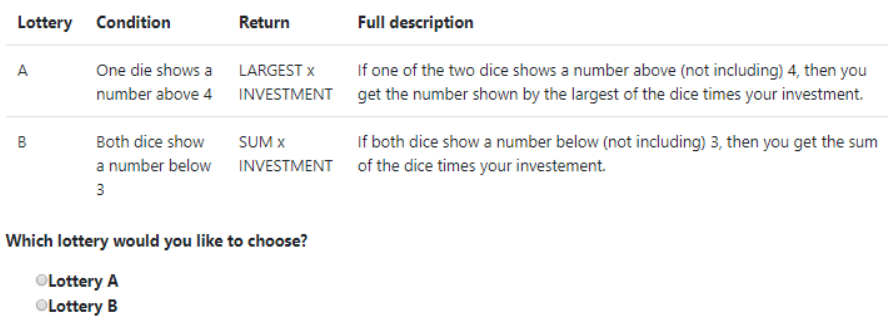

\section{Choice 3}

\begin{tabular}{llll}
\hline Lottery & Condition & Return & Full description \\
\hline A & $\begin{array}{l}\text { One die shows a } \\
\text { number below } 3\end{array}$ & $\begin{array}{l}\text { SUM } x \\
\text { INVESTMENT }\end{array}$ & $\begin{array}{l}\text { If one of the two dice shows a number below (not including) 3, then you } \\
\text { get the sum of the dice times your investment }\end{array}$ \\
\hline B & No condition & $\begin{array}{l}1.25 \mathrm{x} \\
\text { INVESTMENT }\end{array}$ & $\begin{array}{l}\text { You get } 1.25 \text { times your investment regardless of the outcome of the } \\
\text { dice. }\end{array}$
\end{tabular}

Which lottery would you like to choose?

Lottery A

Lottery B

\section{Choice 4}

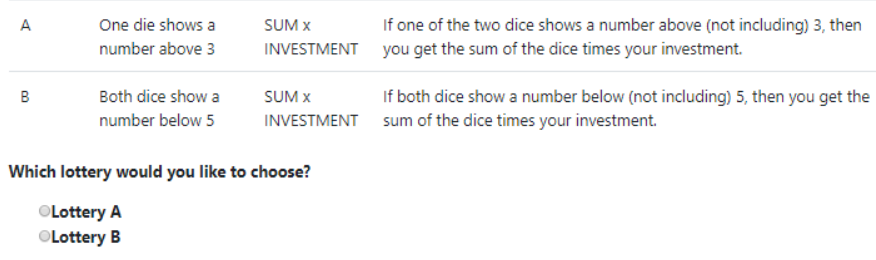




\section{Lottery choice}

On this screen you will make choices that affect yourself.

You will make four choices over lotteries (Choice 1, Choice 2, Choice 3, Choice 4). One of these choices will be randomly selected to be your actual lottery choice. You have been given $\mathbf{5 0}$ points to invest in each lottery that you choose. At the end of the round, two regular six-sided dice (die 1 and die 2) will be thrown. Your payoff will depend on what these two dice show. This means that if choice $\mathbf{B}$ is randomly chosen to be your actual lottery choice and you choose Lottery $\mathbf{2}$ in choice $\mathbf{B}$ then lottery B will specify how your payoff depends on the dice.

Below you see information regarding your own score in the test.

\begin{tabular}{|lr|}
\hline Number of questions & 20 \\
Your score & $\mathbf{9}$ \\
Player 8's score & $\mathbf{0}$ \\
\hline
\end{tabular}

In the picture below it is shown for each possible score, how many participants got that score. Individuals on top of each other got the same score. The blue participant is you.

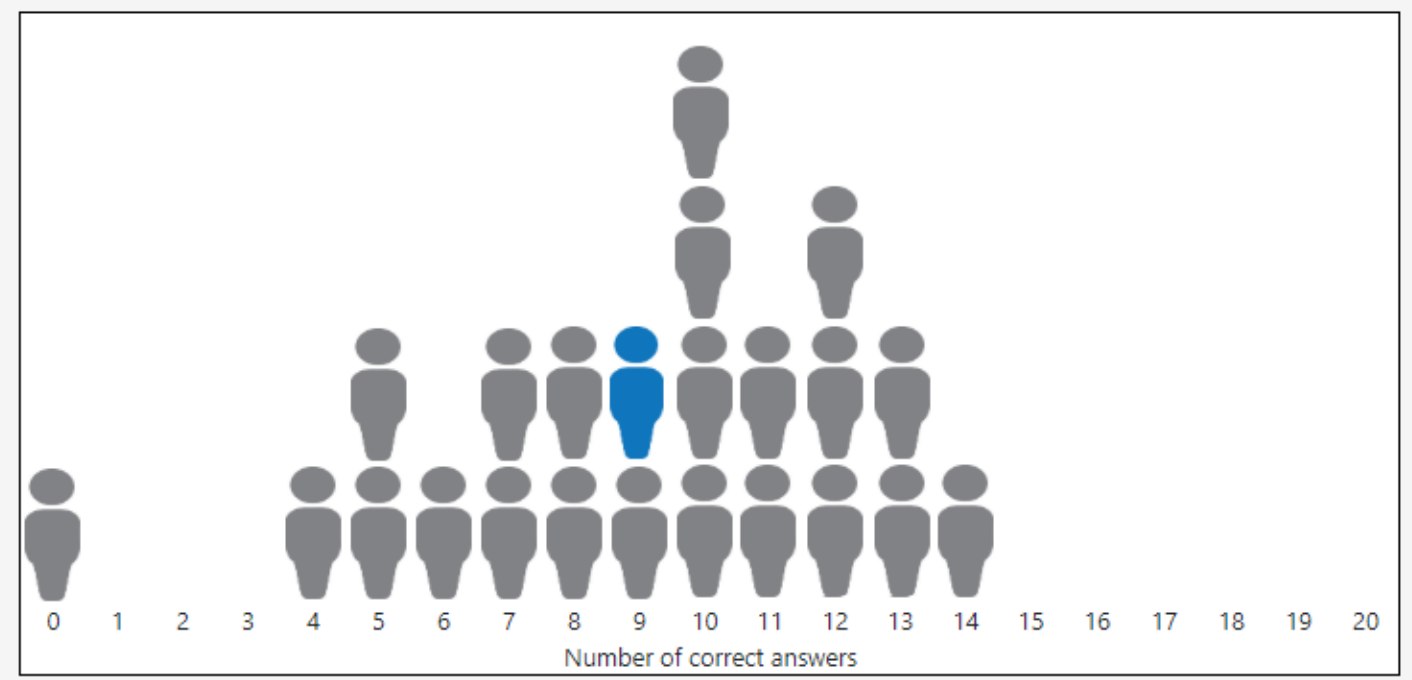

\section{Choice 1}

\begin{tabular}{llll} 
Lottery & Condition & Return & Full description \\
\hline A & $\begin{array}{l}\text { One die shows a } \\
\text { number below } 3\end{array}$ & $\begin{array}{l}\text { SUM } \mathrm{x} \\
\text { INVESTMENT }\end{array}$ & $\begin{array}{l}\text { If one of the two dice shows a number below (not including) 3, then } \\
\text { you get the sum of the dice times your investment }\end{array}$ \\
\hline B & No condition & $\begin{array}{l}1.25 \mathrm{x} \\
\text { INVESTMENT }\end{array}$ & $\begin{array}{l}\text { You get 1.25 times your investment regardless of the outcome of } \\
\text { the dice. }\end{array}$
\end{tabular}

Which lottery would you like to choose?

Lottery A

- Lottery B 


\section{Restriction choice}

On this screen you will make choices that affect Player 8.

Player 8 will make four choices over lotteries. These are the same choices as those you made on the previous screen (and the same lotteries). One the choices will be randomly selected to be his/her actual lottery choice. Player 8 has been given $\mathbf{5 0}$ points to invest in each lottery.

If you wish, you may remove lotteries, so that Player 8 will be unable to choose those lotteries. Note that Player 8 will not make any choices that affect you in this experiment.

Below you see information regarding your own score, as well as Player 8's score in the test.

\begin{tabular}{|lr|}
\hline Number of questions & 20 \\
Your score & $\mathbf{9}$ \\
Player 8's score & $\mathbf{0}$ \\
\hline
\end{tabular}

In the picture below it is shown for each possible score, how many participants got that score. Individuals on top of each other got the same score. blue participant is you. The orange participant is Player 8 .

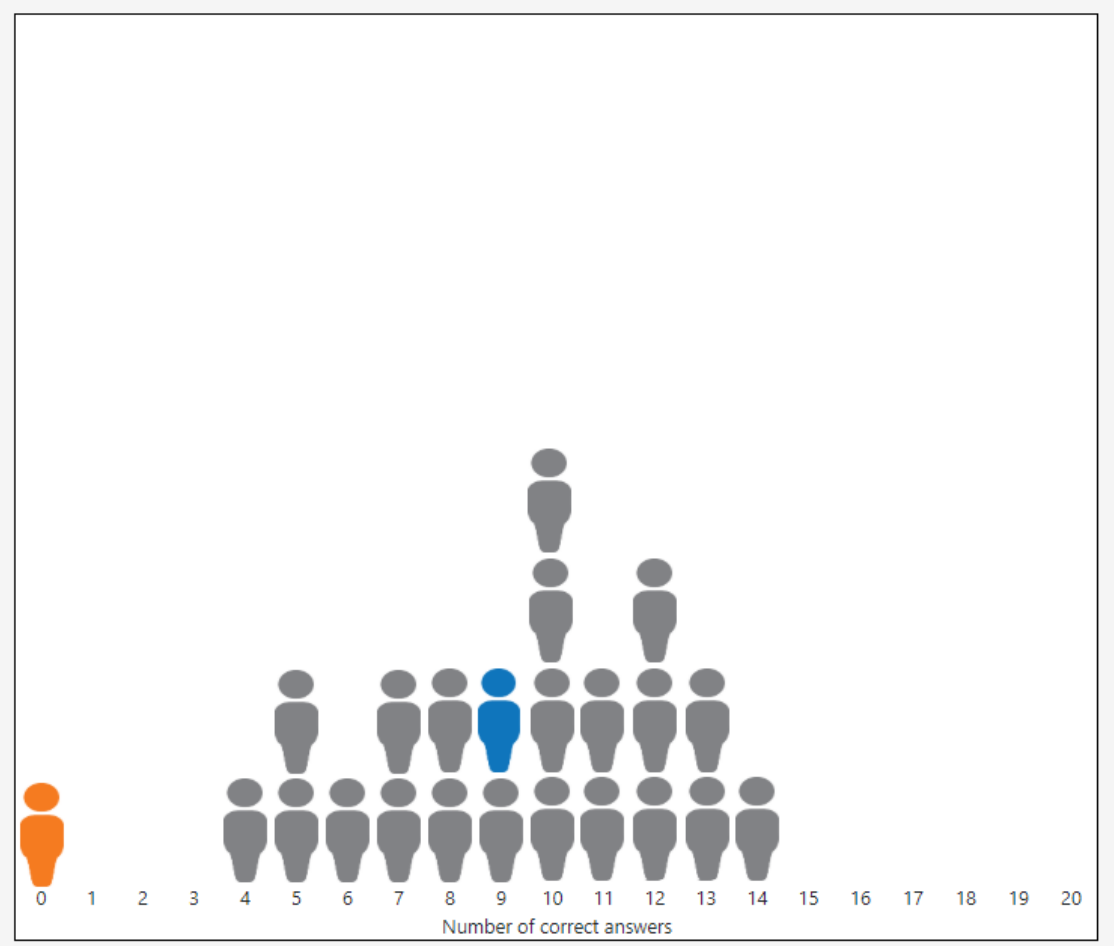

\section{Choice 1}

\begin{tabular}{|c|c|c|c|}
\hline Lottery & Condition & Return & Full description \\
\hline A & $\begin{array}{l}\text { One die shows a } \\
\text { number below } 3\end{array}$ & $\begin{array}{l}\text { SUM } x \\
\text { INVESTMENT }\end{array}$ & $\begin{array}{l}\text { If one of the two dice shows a number below (not including) } 3 \text {, then you } \\
\text { get the sum of the dice times your investment }\end{array}$ \\
\hline B & No condition & $\begin{array}{l}1.25 \mathrm{x} \\
\text { INVESTMENT }\end{array}$ & $\begin{array}{l}\text { You get } 1.25 \text { times your investment regardless of the outcome of the } \\
\text { dice. }\end{array}$ \\
\hline \multicolumn{4}{|c|}{ Would you like to remove any of the lotteries as possible choices for Player 8? } \\
\hline \multicolumn{4}{|c|}{ Remove Lottery A } \\
\hline \multicolumn{4}{|c|}{ Remove Lottery B } \\
\hline \multicolumn{4}{|c|}{ Don't remove any lotteries } \\
\hline
\end{tabular}




\section{Choice 2}

\begin{tabular}{|c|c|c|c|}
\hline Lottery & Condition & Return & Full description \\
\hline A & $\begin{array}{l}\text { One die } \\
\text { shows a } \\
\text { number } \\
\text { below } 3\end{array}$ & $\begin{array}{l}\text { SUM X } \\
\text { INVESTMENT } \\
\text { - DIE1 + DIE2 }\end{array}$ & $\begin{array}{l}\text { If one of the two dice shows a number below (not including) } 3 \text {, then you get } \\
\text { the sum subtracted by the number shown by die } 1 \text { and added by the number } \\
\text { shown by die } 2 \text { times your investment. }\end{array}$ \\
\hline B & $\begin{array}{l}\text { One die } \\
\text { shows a } \\
\text { number } \\
\text { below } 3\end{array}$ & $\begin{array}{l}\text { SUM x } \\
\text { INVESTMENT }\end{array}$ & $\begin{array}{l}\text { If one of the two dice shows a number below (not including) 3, then you } \\
\text { get the sum of the dice times your investment. }\end{array}$ \\
\hline
\end{tabular}

Would you like to remove any of the lotteries as possible choices for Player 8 ?

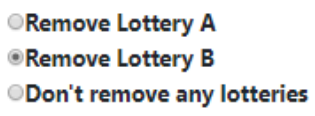

\section{Choice 3}

\begin{tabular}{|c|c|c|c|}
\hline Lottery & Condition & Return & Full description \\
\hline A & $\begin{array}{l}\text { One die shows a } \\
\text { number above } 4\end{array}$ & $\begin{array}{l}\text { LARGEST } x \\
\text { INVESTMENT }\end{array}$ & $\begin{array}{l}\text { If one of the two dice shows a number above (not including) } 4 \text {, then you } \\
\text { get the number shown by the largest of the dice times your investment. }\end{array}$ \\
\hline B & $\begin{array}{l}\text { Both dice show } \\
\text { a number below } \\
3\end{array}$ & $\begin{array}{l}\text { SUM X } \\
\text { INVESTMENT }\end{array}$ & $\begin{array}{l}\text { If both dice show a number below (not including) } 3 \text {, then you get the sum } \\
\text { of the dice times your investement. }\end{array}$ \\
\hline
\end{tabular}

Would you like to remove any of the lotteries as possible choices for Player 8 ?

Remove Lottery A

Remove Lottery B

Don't remove any lotteries

\section{Choice 4}

\begin{tabular}{|c|c|c|c|}
\hline Lottery & Condition & Return & Full description \\
\hline A & $\begin{array}{l}\text { Both dice show a } \\
\text { number below } 5\end{array}$ & $\begin{array}{l}\text { SUM X } \\
\text { INVESTMENT }\end{array}$ & $\begin{array}{l}\text { If both dice show a number below (not including) } 5 \text {, then you get the } \\
\text { sum of the dice times your investment. }\end{array}$ \\
\hline B & $\begin{array}{l}\text { One die shows a } \\
\text { number above } 3\end{array}$ & $\begin{array}{l}\text { SUM X } \\
\text { INVESTMENT }\end{array}$ & $\begin{array}{l}\text { If one of the two dice shows a number above (not including) } 3 \text {, then } \\
\text { you get the sum of the dice times your investment. }\end{array}$ \\
\hline \multicolumn{4}{|c|}{ Would you like to remove any of the lotteries as possible choices for Player $\mathbf{8 ?}$} \\
\hline \multicolumn{4}{|c|}{ Remove Lottery A } \\
\hline \multicolumn{4}{|c|}{ Remove Lottery B } \\
\hline \multicolumn{4}{|c|}{ Don't remove any lotteries } \\
\hline
\end{tabular}




\section{Restricted lottery choice}

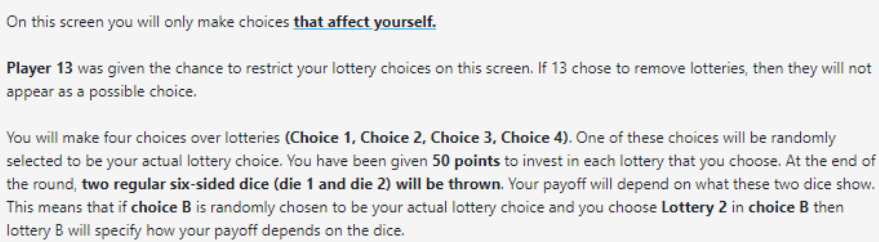

\section{Choice 1}

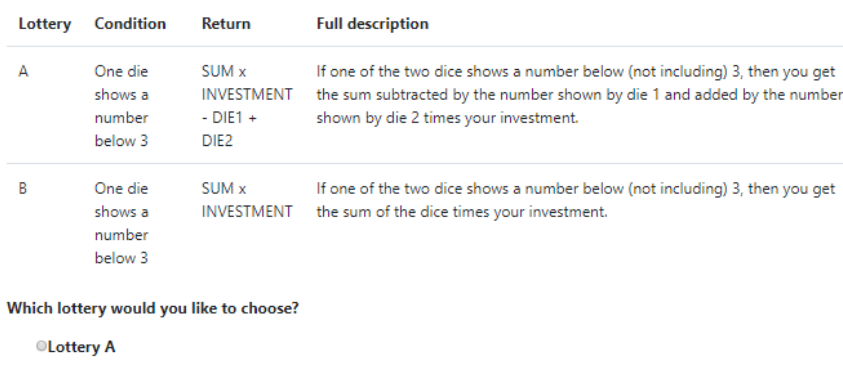

\section{Choice 2}

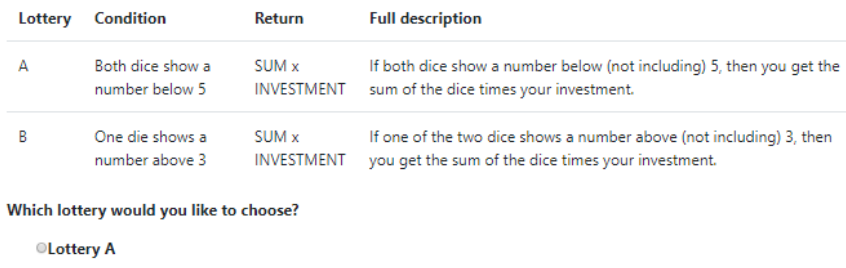

\section{Choice 3}

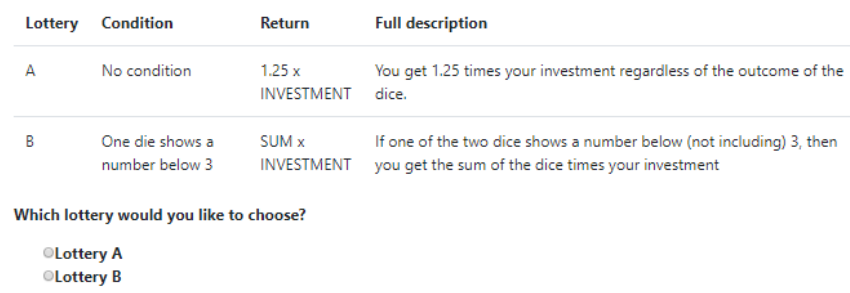

\section{Choice 4}

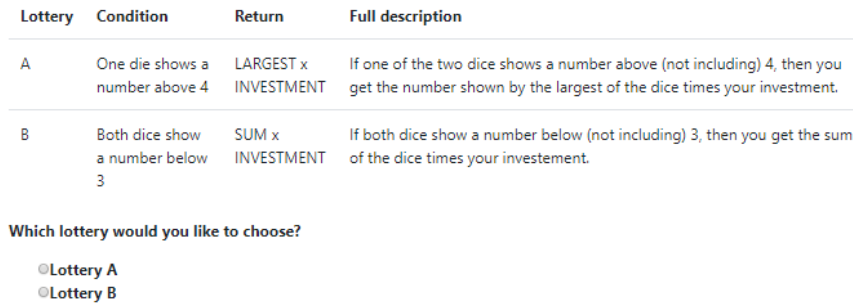




\section{Results}

$\begin{array}{lllll}\text { Round \# } & \text { Die 1 } & \text { Die 2 } & \text { Implemented choice } & \text { Payoff } \\ \mathbf{1} & \mathbf{6} & \mathbf{2} & \text { Choice } \mathbf{1} & \mathbf{0} \text { points }\end{array}$

$\begin{array}{lllll}\text { Round \# } & \text { Die 1 } & \text { Die 2 } & \text { Implemented choice } & \text { Payoff } \\ \mathbf{1} & \mathbf{6} & \mathbf{2} & \text { Choice 1 } & \mathbf{4 0 0} \text { points } \\ 2 & 4 & 3 & \text { Choice } 1 & 63 \text { points } \\ 3 & 1 & 6 & \text { Choice 2 } & 350 \text { points }\end{array}$

The highlighted rows are those that have been selected to be paid out. The highlighted row in the second table was randomly selected.

\section{Your total payoff is 400 points}




\section{Survey}

On this screen screen you see 100 boxes. You may highligt as many boxes as you want in order to open them. For each box you open, you earn 5 points. There is a bomb in one of the boxes. The bomb is placed at random, which means that it may be inside any box with an equal probability. If the bomb is inside one of the boxes you open, then you will get 0 points.

Please choose the amount of boxes you wish to open by clicking below.

You have selected 45 out of 100 boxes.

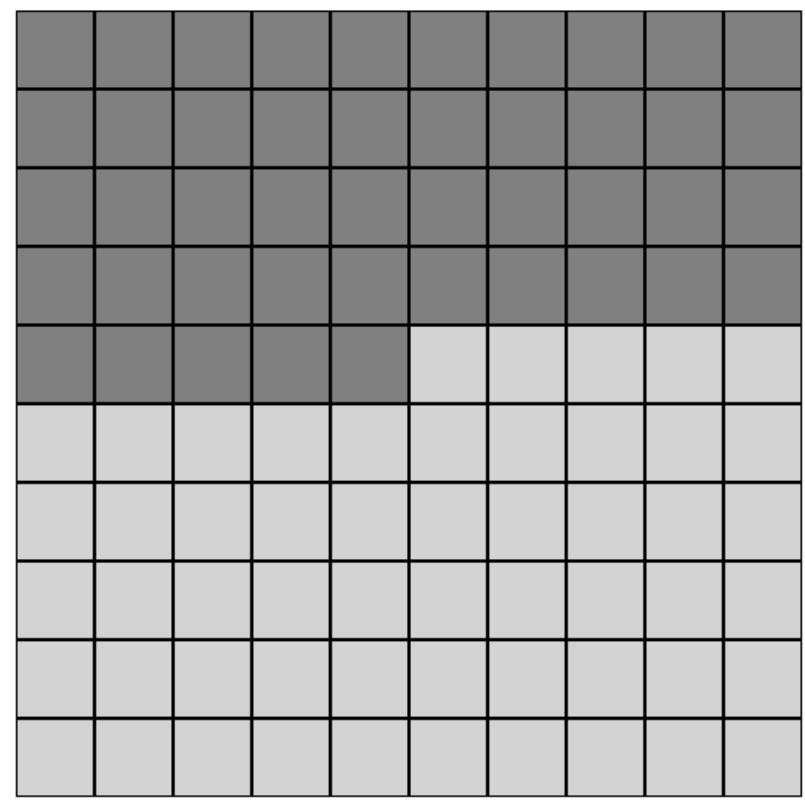

Click outside the box to unselect 


\section{References}

- Mas-Colell, A., Whinston, M. D and J. Green. 1995. Microeconomic Theory. Oxford University Press, inc. New York.

- Inglehart, R., C. Haerpfer, A. Moreno, C. Welzel, K. Kizilova, J. Diez-Medrano, M. Lagos, P. Norris, E. Ponarin \& B. Puranen et al. (eds.). 2014. World Values Survey: Round Six - Country-Pooled Datafile. 